NASA/TM-2009-215609

AIAA-2009-1237

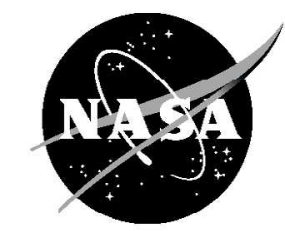

Core Noise Diagnostics of Turbofan Engine Noise Using Correlation and Coherence Functions

Jeffrey $H$. Miles

Glenn Research Center, Cleveland, Ohio 


\section{NASA STI Program . . . in Profile}

Since its founding, NASA has been dedicated to the advancement of aeronautics and space science. The NASA Scientific and Technical Information (STI) program plays a key part in helping NASA maintain this important role.

The NASA STI Program operates under the auspices of the Agency Chief Information Officer. It collects, organizes, provides for archiving, and disseminates NASA's STI. The NASA STI program provides access to the NASA Aeronautics and Space Database and its public interface, the NASA Technical Reports Server, thus providing one of the largest collections of aeronautical and space science STI in the world. Results are published in both non-NASA channels and by NASA in the NASA STI Report Series, which includes the following report types:

- TECHNICAL PUBLICATION. Reports of completed research or a major significant phase of research that present the results of NASA programs and include extensive data or theoretical analysis. Includes compilations of significant scientific and technical data and information deemed to be of continuing reference value. NASA counterpart of peer-reviewed formal professional papers but has less stringent limitations on manuscript length and extent of graphic presentations.

- TECHNICAL MEMORANDUM. Scientific and technical findings that are preliminary or of specialized interest, e.g., quick release reports, working papers, and bibliographies that contain minimal annotation. Does not contain extensive analysis.

- CONTRACTOR REPORT. Scientific and technical findings by NASA-sponsored contractors and grantees.
- CONFERENCE PUBLICATION. Collected papers from scientific and technical conferences, symposia, seminars, or other meetings sponsored or cosponsored by NASA.

- SPECIAL PUBLICATION. Scientific, technical, or historical information from NASA programs, projects, and missions, often concerned with subjects having substantial public interest.

- TECHNICAL TRANSLATION. Englishlanguage translations of foreign scientific and technical material pertinent to NASA's mission.

Specialized services also include creating custom thesauri, building customized databases, organizing and publishing research results.

For more information about the NASA STI program, see the following:

- Access the NASA STI program home page at http://www.sti.nasa.gov

- E-mail your question via the Internet to help@ sti.nasa.gov

- Fax your question to the NASA STI Help Desk at $443-757-5803$

- Telephone the NASA STI Help Desk at 443-757-5802

- Write to: NASA Center for AeroSpace Information (CASI) 7115 Standard Drive Hanover, MD 21076-1320 


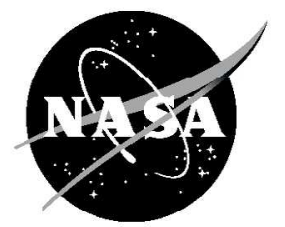

\title{
Core Noise Diagnostics of Turbofan Engine Noise Using Correlation and Coherence Functions
}

\author{
Jeffrey $H$. Miles \\ Glenn Research Center, Cleveland, Ohio
}

Prepared for the

47th Aerospace Sciences Meeting

sponsored by the American Institute of Aeronautics and Astronautics

Orlando, Florida, January 5-8, 2009

National Aeronautics and

Space Administration

Glenn Research Center Cleveland, Ohio 44135 
This report contains preliminary findings, subject to revision as analysis proceeds.

Trade names and trademarks are used in this report for identification only. Their usage does not constitute an official endorsement, either expressed or implied, by the National Aeronautics and Space Administration.

This work was sponsored by the Fundamental Aeronautics Program at the NASA Glenn Research Center.

Level of Review: This material has been technically reviewed by technical management.

Available from

NASA Center for Aerospace Information 7115 Standard Drive

Hanover, MD 21076-1320
National Technical Information Service 5285 Port Royal Road Springfield, VA 22161

Available electronically at http://gltrs.grc.nasa.gov 


\title{
Core Noise Diagnostics of Turbofan Engine Noise Using Correlation and Coherence Functions
}

\author{
Jeffrey H. Miles \\ National Aeronautics and Space Administration \\ Glenn Research Center \\ Cleveland, Ohio 44135
}

\begin{abstract}
Summary
Cross-correlation and coherence functions are used to look for periodic acoustic components in turbofan engine combustor time histories, to investigate direct and indirect combustion noise source separation based on signal propagation time delays, and to provide information on combustor acoustics. Using the cross-correlation function, time delays were identified in all cases, clearly indicating the combustor is the source of the noise. In addition, unfiltered and low-pass filtered at $400 \mathrm{~Hz}$ signals had a cross-correlation time delay near $90 \mathrm{~ms}$, while the low-pass filtered at less than $400 \mathrm{~Hz}$ signals had a cross-correlation time delay longer than $90 \mathrm{~ms}$. Low-pass filtering at frequencies less than $400 \mathrm{~Hz}$ partially removes the direct combustion noise signals. The remainder includes the indirect combustion noise signal, which travels more slowly because of the dependence on the entropy convection velocity in the combustor. Source separation of direct and indirect combustion noise is demonstrated by proper use of low-pass filters with the cross-correlation function for a range of operating conditions. The results may lead to a better idea about the acoustics in the combustor and may help develop and validate improved reduced-order physics-based methods for predicting direct and indirect combustion noise.
\end{abstract}

\section{Nomenclature}

$B_{e} \quad$ resolution bandwidth, $\mathrm{Hz}, B_{e}=1 / T_{d}=r_{s} / N=2 \mathrm{~Hz}$

$c_{c} \quad$ combustor region speed of sound, $\mathrm{m} / \mathrm{s}$

$D \quad$ propagation time delay or lag, $\mathrm{s}$

$f_{c} \quad$ upper frequency limit, $f_{c}=1 / 2 \Delta t=r_{s} / 2, \mathrm{~Hz}(32768 \mathrm{~Hz})$

$f_{L} \quad$ cutoff frequency of low-pass filter

$H_{L P\left[f_{L}\right]}(j \omega)$ low-pass filter transfer function with cutoff frequency, $f_{L}$

$L_{c} \quad$ combustor region length, $\mathrm{m}$

$L_{y} \quad$ number of frequencies, $f_{c} / \Delta f=N / 2$ (16 384)

$M_{c} \quad$ combustor region Mach number

$N \quad$ segment length, number of data points per segment (32 768)

$n_{o} \quad$ number of overlapped data segments/blocks

$n_{s} \quad$ number of disjoint (independent) data segments/blocks, $n_{s}=B_{e} T_{\text {total }} \approx 128$

$P_{\mathrm{I}} \quad$ confidence interval percent value used to calculate coherence threshold

$r \quad$ microphone radial location, $\mathrm{m}(30.48 \mathrm{~m})$

$R_{x} \quad$ autocorrelation function

$r_{s} \quad$ sample rate, samples/s $(65536)$

$R_{x y} \quad$ cross-correlation function

$T_{\text {total }}$ total record length, $\mathrm{s}(\approx 70 \mathrm{~s})$

$t$ time, $\mathrm{s}$

$T_{c} \quad$ temperature in combustor, ${ }^{\circ} \mathrm{K}$

$T_{d}(i) \quad$ record length of segment $i, N / r_{s}, 0.5 \mathrm{~s}$ 


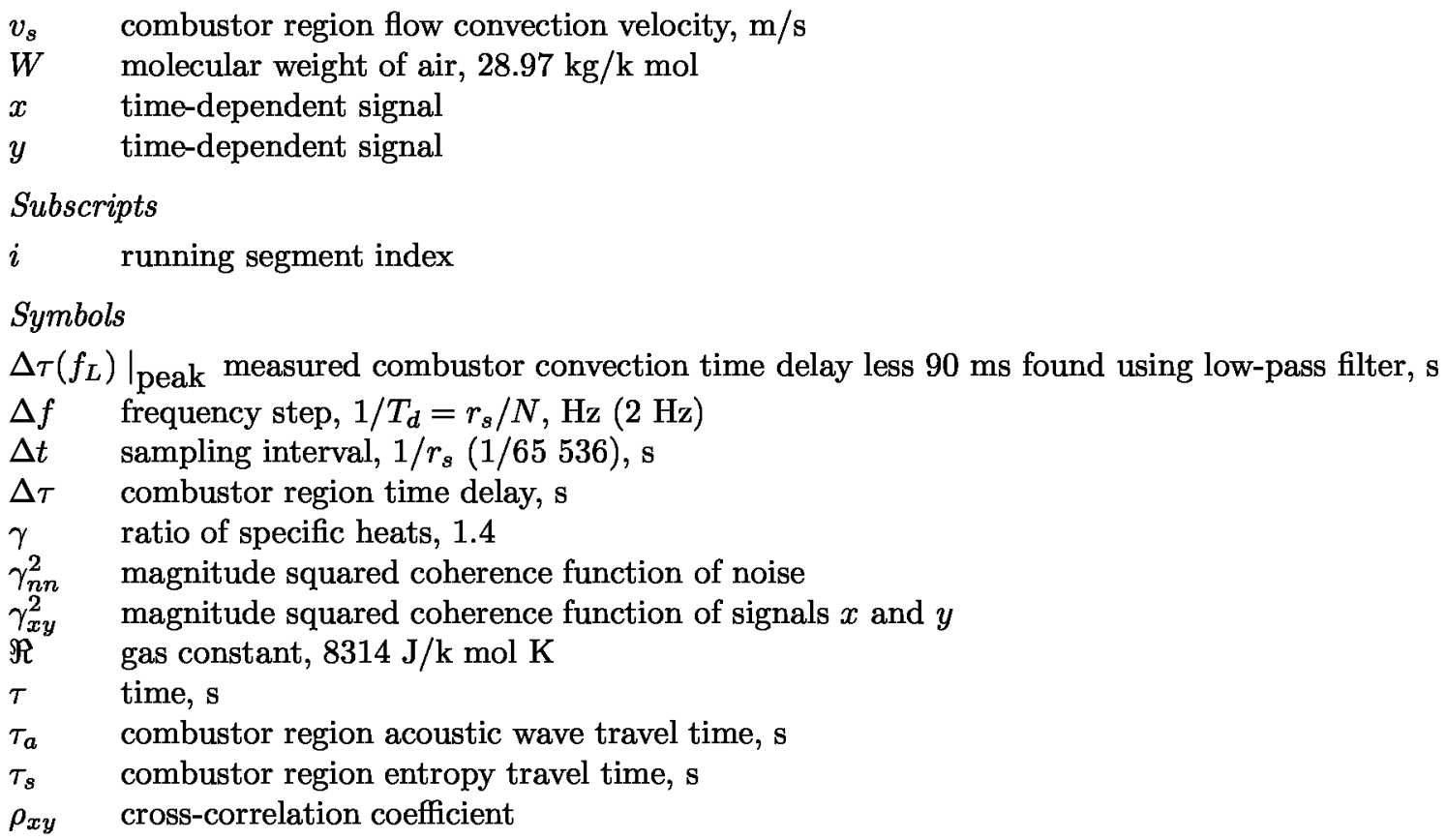

\section{Introduction}

The study of turbofan engine core noise is part of the NASA Foundational Research Program to develop noise diagnostic tools, noise prediction schemes, and noise reduction technologies. Combustion noise, both direct and indirect, is an important contributor to low-frequency core noise. Combustion noise is difficult to study because hydrodynamic and acoustic pressure fluctuations are intermixed at the source location. In addition, much of the far-field noise is not correlated with the combustor and/or turbine internal noise. However, the part that is correlated can be studied using signal cross-correlation functions and coherence functions. The goal of this study is to improve understanding of the acoustics in combustors that ultimately will enable development of improved reduced-order physics-based methods for predicting direct and indirect combustor noise.

The report compares time domain and spectral domain methods using cross-correlation functions and coherence functions. The methods are applied to data from a dual-spool TECH977 turbofan engine. Acoustic data from the same TECH977 engine test program are discussed by Miles (2008,2009), ${ }^{1,2}$ Mendoza et al. (2008), ${ }^{3}$ Weir and Mendoza (2008), ${ }^{4}$ Schuster (2008), ${ }^{5}$ Royalty and Schuster (2008), ${ }^{6}$ Dougherty and Mendoza (2008), ${ }^{7}$ and Weir (2008) ${ }^{8}$ The research discussed is an extension of the study of the combustion noise of the TECH977 engine conducted by Miles (2008), ${ }^{1}$ using a coherent output power spectral domain coherence function approach.

The core noise components of the dual-spool turbofan engine were separated by Miles (2008) ${ }^{1}$ using coherence functions. A source location technique was used that adjusted the time delay between the combustor pressure sensor signal and the far-field microphone signal to maximize the coherence and remove as much variation of the phase angle with frequency as possible. For the $130^{\circ}$ microphone, a $90.03 \mathrm{~ms}$ time shift worked best for the frequency band from $0-200 \mathrm{~Hz}$, while a $86.98 \mathrm{~ms}$ time shift worked best for the frequency band from $200-400 \mathrm{~Hz}$. Hence, the $0-200 \mathrm{~Hz}$ band signal took more time than the $200-400 \mathrm{~Hz}$ band signal to travel the same distance. This suggests the $0-200 \mathrm{~Hz}$ coherent cross-spectral density band is partly due to indirect combustion noise attributed to entropy fluctuations, which travel at a low-flow velocity in the combustor until interactions with the turbine pressure gradient produce indirect combustion noise. The indirect noise source was studied by Pickett (1975) ${ }^{9}$ Cumpsty and Marble (1977), ${ }^{10,11}$ Cumpsty (1979), ${ }^{12}$ and Gliebe et al. (2000). ${ }^{13}$ The signal in the $200-400 \mathrm{~Hz}$ frequency band is attributed mostly to direct combustion noise. The method discussed herein is successful because acoustic and temperature fluctuations caused by hot spot convection were found by Miles $(1983 a)^{14}$ to be related by a linear transfer function that includes a convective time delay. This experiment involved the measurements of pressure and temperature disturbances in a long tube connected to a combustor. This linear connection of entropy and 
pressure fluctuations implies the direct and indirect combustion noise are dependent.

Cross-correlation functions are discussed in standard signal processing texts such as those by Bendat and Piersol (1966), ${ }^{15}$ Bendat and Piersol (1971), ${ }^{16}$ Bendat and Piersol (1980), ${ }^{17}$ Childers and Durling $(1975),{ }^{18}$ Kay (1987) ${ }^{19}$ and Stearns and David (1993) ${ }^{20}$ Computational methods are discussed by Childers and Durling (1975) ${ }^{18}$ Kay (1987), ${ }^{19}$ and Stearns and David (1993). ${ }^{20}$ The cross-correlation function was used to detect periodic signals in noise by Lee (1950). ${ }^{21}$ White $(1969)^{22}$ used the cross-correlation function and filters to look for propagation time delays in a system with periodic signals.

Cross-correlation functions were used by Karchmer and Reshotko $(1976)^{23}$ to study propagation time delays from a AVCO-Lycoming YF-102 turbofan engine combustor to a far-field microphone located at a $120^{\circ}$ polar angle. Combustion noise below $250 \mathrm{~Hz}$ was attributed to an indirect combustion noise source. Cross-correlation functions were obtained using signals low-pass-filtered to remove frequencies above 1600 $\mathrm{Hz}$ or $240 \mathrm{~Hz}$. Karchmer $(1977 \mathrm{a})^{24}$ presented additional results in his dissertation. In particular, crosscorrelation functions were shown again using signals low-pass-filtered to remove frequencies above $240 \mathrm{~Hz}$. Reshotko and Karchmer (1980 ${ }^{25}$ presented similar test results for the Pratt \& Whitney JT15D turbofan engine. Combustion noise below $250 \mathrm{~Hz}$ was attributed a direct combustion noise source. Cross-correlation functions were shown using signals low-pass-filtered to remove frequencies above $240 \mathrm{~Hz}$. Mathews et al. $(1977 \mathrm{~b})^{26}$ studied propagation time delays from a Pratt \& Whitney JT8D-109 engine combustor to the far field using the cross-correlation function and attributed the noise source to the combustor. The report attributed the noise to direct combustion noise and cited calculations that indicate indirect combustion noise was much lower than direct combustion noise. Using the cross-correlation function, Shivashankara $(1978)^{27}$ studied propagation time delays from an auxiliary power unit. Combustion noise below $400 \mathrm{~Hz}$ was attributed by Shivashankara $(1978)^{27}$ to a direct combustion noise source. Cross-correlation functions were shown by Shivashankara $(1978)^{27}$ using signals filtered to remove frequencies above $1000 \mathrm{~Hz}$. More recently, Harper-Bourne et al. (2008) ${ }^{28}$ used the cross-correlation function to study combustion noise of a turbofan demonstrator engine. The engine study program used internal and external sensors. The method revealed delay times from the internal combustor sensor to the far-field microphone, even though the signal correlated contained both periodic and random components. In addition, indirect combustion noise has been investigated numerically and with model scale experiments by Schemel et al. (2004), ${ }^{29}$ Richter et al. (2005), ${ }^{30}$ and Bake et al..$^{31-33}$

The fundamental premise of this report is that filtering to remove frequencies above $400 \mathrm{~Hz}$ leaves the combined direct and indirect combustion noise unchanged in the signal. Filtering to remove frequencies above $200 \mathrm{~Hz}$ leaves the indirect combustion noise mostly unchanged. In addition, the low-pass filters are designed to eliminate phase angle modifications and to leave the signal delay time identified as the location of a peak of the correlation function of random noise at the proper time value.

Fundamental to the interpretation of the results presented is that entropy waves or hot spots travel at the flow velocity, which is only a fraction of the speed of sound. According to Hill and Peterson, ${ }^{34}$ the average axial velocity of the combustor reactants, $v_{s}$, is of the order of $30 \mathrm{~m} / \mathrm{s}$. The speed of sound in a combustor, $c_{c}$, is generally calculated based on the assumption that the air is a perfect gas. ${ }^{34-36}$

$$
c_{c}=\sqrt{\gamma \Re T_{c} / W}
$$

As reported by Hill and Peterson, ${ }^{34}$ typical turbine inlet temperatures are of the order of $1600^{\circ} \mathrm{K}$. Consequently, the speed of sound, $c_{c}$, is of the order of $800 \mathrm{~m} / \mathrm{s}$. Thus, the Mach number of the hot spots is about 0.0375 . This assumption is not a practical limitation to the present investigation. However, the use of the perfect gas assumption is subject to certain limitations as pointed out by Barrett and Suomi (1949) $)^{37}$ and Cramer (1993), ${ }^{38}$ such as the assumption that the incremental pressure due to the sound wave is very small compared to the static pressure of the medium; the frequencies are low so that $\gamma$ is independent of frequency.

This report examines signals at the $130^{\circ}$ microphone. Engine operating conditions of $48,54,60$, and 71 percent of maximum power are evaluated. Results are presented for an unfiltered condition, and after low-pass filtering to remove frequencies above $400 \mathrm{~Hz}, 300 \mathrm{~Hz}, 200 \mathrm{~Hz}, 150 \mathrm{~Hz}$, and $100 \mathrm{~Hz}$. In addition, for the $400 \mathrm{~Hz}$ and $150 \mathrm{~Hz}$ low-pass filtered signals, aligned coherence functions and coherent combustion power results are shown using a time shift of 86.98 and $90.03 \mathrm{~ms}$. In the next section, the engine noise data and analysis are presented. 


\section{Engine Noise Data and Analysis}

\section{A. Engine test data}

The static engine test was conducted at Honeywell's San Tan Outdoor Acoustic test facility. A polar array of 32 ground-plane microphones was used. Each B \& K 4134 microphone in an inverted stand with a 7 -mm ground spacing was placed on a $100 \mathrm{ft}$ radius. The microphones were positioned from $5^{\circ}$ to $160^{\circ}$ (relative to the inlet) in $5^{\circ}$ increments. The microphone at $130^{\circ}$ was used in this study.

The dual-spool, turbofan engine has a direct drive, wide chord fan connected by a long shaft to the low-pressure turbine spool and a high-pressure compressor connected by a concentric short shaft to the turbine high-pressure spool. The fan diameter is $34.2 \mathrm{in}$. The combustor design is a straight-through-flow annular geometry with 16 fuel nozzles and 2 igniters. One of the igniters is replaced by a pressure transducer, which is identified herein as CIP1. The dependent source separation technique used to identify direct and indirect combustion noise uses data from the CIP1 transducer and a far-field microphone.

The data acquisition system had a sampling rate of $65536 \mathrm{~Hz}$ and a sampling duration of roughly $70 \mathrm{~s}$. This permitted data reduction using 254 overlapped ensemble averages at a bandwidth resolution of 2 Hz. Further signal estimation parameters are shown in Table 1.

Table 1 Spectral estimate parameters

\begin{tabular}{|c|c|}
\hline Parameter & Value \\
\hline Segment length, (data points per segment), $N$ & 32768 \\
\hline Sample rate, $r_{s}$, samples $/ \mathrm{s}$ & 65536 \\
\hline Segment length, $T_{d}=N / r_{s}, \mathrm{~s}$ & 0.500 \\
\hline Sampling interval, $\Delta t=1 / r_{s}, \mathrm{~s}$ & $1 / 65536$ \\
\hline Bandwidth resolution, $B_{e}=\Delta f=1 / T_{d}=r_{s} / N, \mathrm{~Hz}$ & 2.0 \\
\hline Upper frequency limit, $f_{c}=1 / 2 \Delta t=r_{s} / 2, \mathrm{~Hz}$ & 32768 \\
\hline Number of frequencies, $L y=f_{c} / \Delta f=N / 2$ & 16384 \\
\hline Propagation time delay $/ \mathrm{lag}\left(T=9^{\circ} \mathrm{C}, r=30.48 \mathrm{~m}\right) D=5927 / 65536, \mathrm{~s}$ & 0.09044 \\
\hline Number of independent samples, $n_{s}$ & 128 \\
\hline Overlap & 0.50 \\
\hline Sample length, $T_{\text {total }}, \mathrm{s}$ & $\approx 70$ \\
\hline
\end{tabular}

\section{B. Correlation functions}

The autocorrelation function describes the general dependence of the values of data at one time on the value at another time. The autocorrelation function is

$$
R_{x x}(\tau)=\lim _{T \rightarrow \infty} \frac{1}{T} \int_{0}^{T} x(t) x(t+\tau) d t
$$

The cross-correlation function describes the general dependence of the values of one set of data at one time on the value of another set of data at another time. The cross-correlation function is

$$
R_{x y}(\tau)=R_{y x}(-\tau)=\lim _{T \rightarrow \infty} \frac{1}{T} \int_{0}^{T} x(t) y(t+\tau) d t
$$

Note, the cross-correlation function is not symmetric in time about zero.

The normalized cross-correlation function known as the cross-correlation function coefficient (normalized cross-covariance function) used herein to plot the cross-correlation functions is defined as

$$
\rho_{x y}(\tau)=\rho_{y x}(-\tau)=\frac{R_{x y}(\tau)}{\sqrt{R_{x x}(0) R_{y y}(0)}}
$$

by Bendat and Piersol. ${ }^{16,17}$ While the total cross-correlation functions are calculated, only the positive time delay is shown. 


\section{Filtering}

The 100, 200, 300, and $400 \mathrm{~Hz}$ low-pass filters used are three-section Butterworth filters. Filter design was done using bilinear transformation following a method described by Stearns and David. ${ }^{20}$ These filter parameters are given in Tables 2a, 2c, 2d, and $2 \mathrm{e}$.

To see if the results depended on the filter design approach, a non-Butterworth filter was used as a $150 \mathrm{~Hz}$ filter with coefficients shown in Table 2b. For the first section, this filter uses the second-section filter values of the $300 \mathrm{~Hz}$ filter shown in Table 2d. For the second and third section, this filter uses the third-section filter values of the $300 \mathrm{~Hz}$ filter shown in Table 2d. The $150 \mathrm{~Hz}$ filter has a larger transition band than a properly designed Butterworth filter.

To make certain the filters introduce no phase angle modification, the filter for each segment is applied to the forward time series and then again, with the time reversed. The time series reversal is then removed before processing the next segment or quitting. This procedure is discussed by Kormylo and Jain ${ }^{39}$ and by Hamming. ${ }^{40}$ Note the effective filter function is the square of the absolute value of filter function designed.

Table 2a $100 \mathrm{~Hz}$ lowpass filter parameters

\begin{tabular}{llll}
\hline \hline Parameter & Values & & \\
\hline$A_{1}(z)$ & -1.994957877158 & 0.995049566793 & \\
$B_{1}(z)$ & 0.000022922409 & 0.000045844817 & 0.000022922409 \\
$A_{2}(z)$ & -1.986441602897 & 0.986532901119 & \\
$B_{2}(z)$ & 0.000022824555 & 0.000045649111 & 0.000022824555 \\
$A_{3}(z)$ & -1.981557756270 & 0.981648830027 & \\
$B_{3}(z)$ & 0.000022768439 & 0.000045536878 & 0.000022768439 \\
\hline \hline
\end{tabular}

Table $2 \mathrm{~b} 150 \mathrm{~Hz}$ lowpass filter parameters

\begin{tabular}{llll}
\hline \hline Parameter & Values & & \\
\hline$A_{1}(z)$ & -1.959329632211 & 0.960140349842 & \\
$B_{1}(z)$ & 0.000202679408 & 0.000405358816 & 0.000202679408 \\
$A_{2}(z)$ & -1.945140180302 & 0.945945026722 & \\
$B_{2}(z)$ & $0.0002012116 \mathrm{a} 05$ & 0.000402423210 & 0.000201211605 \\
$A_{3}(z)$ & -1.945140180302 & 0.945945026722 & \\
$B_{3}(z)$ & 0.000201211605 & 0.000402423210 & 0.000201211605 \\
\hline \hline
\end{tabular}

Table 2c $200 \mathrm{~Hz}$ lowpass filter parameters

\begin{tabular}{llll}
\hline \hline Parameter & Values & & \\
\hline$A_{1}(z)$ & -1.989758186880 & 0.990124031531 & \\
$B_{1}(z)$ & 0.000091461163 & 0.000182922325 & 0.000091461163 \\
$A_{2}(z)$ & -1.972884422898 & 0.973247165073 & \\
$B_{2}(z)$ & 0.000090685544 & 0.000181371087 & 0.000090685544 \\
$A_{3}(z)$ & -1.963272029823 & 0.963633004625 & \\
$B_{3}(z)$ & 0.000090243701 & 0.000180487401 & 0.000090243701 \\
\hline \hline
\end{tabular}

\section{White noise results}

To demonstrate the filtering process, a study was conducted using white noise generated by use of a "Mersenne Twister" random number generator. ${ }^{41}$ Figure 1 shows the effect of each filter on the signal amplitude. 
Table 2d $300 \mathrm{~Hz}$ lowpass filter parameters

\begin{tabular}{llll}
\hline \hline Parameter & Values & & \\
\hline$A_{1}(z)$ & -1.984402564179 & 0.985223656312 & \\
$B_{1}(z)$ & 0.0002052730330 & 0.000410546067 & 0.000205273033 \\
$A_{2}(z)$ & -1.959329632211 & 0.960140349842 & \\
$B_{2}(z)$ & 0.000202679408 & 0.000405358816 & 0.000202679408 \\
$A_{3}(z)$ & -1.945140180302 & 0.945945026722 & \\
$B_{3}(z)$ & 0.000201211605 & 0.000402423210 & 0.000201211605 \\
\hline \hline
\end{tabular}

Table 2e $400 \mathrm{~Hz}$ lowpass filter parameters

\begin{tabular}{llll}
\hline \hline Parameter & Values & & \\
\hline$A_{1}(z)$ & -1.978892639460 & 0.980348696212 & \\
$B_{1}(z)$ & 0.000364014188 & 0.000728028376 & 0.000364014188 \\
$A_{2}(z)$ & -1.945778355457 & 0.947210046928 & \\
$B_{2}(z)$ & 0.000357922868 & 0.000715845735 & 0.000357922868 \\
$A_{3}(z)$ & -1.927159619380 & 0.928577611302 & \\
$B_{3}(z)$ & 0.000354497980 & 0.000708995961 & 0.000354497980 \\
\hline \hline
\end{tabular}

Figure 2 shows cross-correlation functions generated using random-number-generated white noise and random-number-generated white noise displaced by $D_{T}=86.98 \mathrm{~ms}$. Each plot has the cross-correlation function of the unfiltered signals and the signals filtered by the $100 \mathrm{~Hz}$ low-pass filter. Figures 2 (a) through (d) have the results of the $400,300,200$, and $150 \mathrm{~Hz}$ low-pass filters, respectively. The location of the peak value is constant, independent of the filter design. The width of the peak increases as the filter design frequency is reduced.

\section{E. Coherence threshold}

A minimum threshold of the magnitude squared coherence, $\gamma_{n n}^{2}$ was obtained using the $P_{\mathrm{I}}=$ percent confidence interval as discussed by Carter, ${ }^{42,43}$ Halliday, ${ }^{44}$ and Brillinger. ${ }^{45}$ This threshold is given by

$$
\gamma_{n n}^{2}=1-\left(1-P_{\mathrm{I}}\right)^{1 /\left(n_{s}-1\right)}
$$

and represents the coherence of two independent time series, calculated using an average of $n_{s}$ independent finite length sample segments.

Miles $^{46}$ shows that instead of relying on the confidence interval given by Eq. (5), which is based on a statistical theory, to obtain a threshold value for $\gamma_{n n}^{2}(f)$, one can use a deliberately unaligned time history to create the threshold value. If one of the time histories is shifted by a time delay more than the segment/block length, $T_{d}=N / r_{s}$, then the two time histories are totally independent unless tones are present. This deliberate decorrelation establishes a coherence threshold and also identifies any tones in the signals. Shifting the signals by this time delay removes the coherence of random noise (identified frequently as broadband noise) but leaves the coherence of periodic functions (identified frequently as tones). Miles ${ }^{46}$ found out that replacing $n_{s}$ with $n_{o}$ in Eq. (5), where $n_{o}$ is the number of overlapping segments, gives a good estimate of the coherence squared noise threshold, $\gamma_{n n}^{2}(f)$. Thus, for a 95 percent confidence interval, the noise floor is $\gamma_{n n}^{2}=0.012\left(n_{o}=254\right)$, where the number of overlapped averages is used, rather than the number of independent averages.

\section{Results}

\section{A. Cross-correlation with and without filtering}

The sequence of low-pass filters, discussed in the previous section, is applied to the combustor pressure transducer signal and far-field microphone signal. The signal resulting from using the $400 \mathrm{~Hz}$ low- 
pass filter contains both indirect and direct combustion noise. By applying further low-pass filters in the sequence, (i.e., $300 \mathrm{~Hz}, 200 \mathrm{~Hz}, 150 \mathrm{~Hz}$, and $100 \mathrm{~Hz}$ ), the resulting signal will have a decreasing amount of direct combustion noise. The signal resulting from using the $100 \mathrm{~Hz}$ low-pass filter contains mainly indirect combustion noise.

The cross-correlation functions between the microphone at $130^{\circ}$ and the combustor pressure sensor are presented in Figs. 3 through 10. Figures 4, 6, 8, and 10 show the cross-correlation functions in the time region from $80 \mathrm{~ms}$ to $100 \mathrm{~ms}$, which contain the peak value. The left side of the peak is determined by the direct combustion noise, which moves at acoustic speed along its full path. The right side of the peak in the region is controlled by the indirect combustion noise, which initially propagates with the mean flow velocity.

The combustion noise spectrum has a limited frequency range. For this particular engine, this limit is about $400 \mathrm{~Hz}$. Figure 2 shows that the cross-correlation of two band limited signals is smeared in the time domain. Consequently, one might expect to see in Figures 4, 6, 8, and 10 a cross-correlation function with a one smeared peak due to direct combustion noise and one smeared peak due to indirect combustion noise. Examination of the cross-correlation functions shows this is the case only for the 48 percent of maximum power operating condition (see Figs. 3 d-f and 4).

However, as the low-pass filter cutoff frequency is decreased, more direct combustion noise, which controls the left side of the peak, is removed and the temporal smearing is increased. For low-pass filters with a cutoff frequency less than $150 \mathrm{~Hz}$ one sees only a single peak (Fig. 4a). In addition, the location of the double-peak or single-peak maximum value shifts to larger time delays as the low-pass filter cutoff frequency is decreased. The no-filter case and the cases filtered with the $200-400 \mathrm{~Hz}$ low-pass filters show a first peak near $90 \mathrm{~ms}$ and a second smaller peak near $95 \mathrm{~ms}$. The peak using the $100 \mathrm{~Hz}$ low-pass filter occurs at $92 \mathrm{~ms}$.

At the three higher operating conditions, the two-peak phenomena are not observed in crosscorrelations made using the combustor pressure sensor with the $130^{\circ}$ microphone; only a single peak crosscorrelation is observed. The reason that only a single peak is detected is not clear, but it is possible that the relative amount of indirect combustion noise in the signal is decreased, making its detection as a discrete peak more difficult at these three higher power settings. Another possibility is that the ripple observed at the 48 percent operating condition is due to a convective entropy feedback mechanism that enhances the indirect combustion noise signal for this case. However, in all cases, the single peak or the left peak, where a double peak occurs, shifts to the right as the low-pass filter cutoff frequency is decreased.

The resulting delay time values of the peak are shown in Table 3. For the cases where no filter is used or the case when the $400 \mathrm{~Hz}$ low-pass filter was used, this time corresponds to about 90 ms. Peak values of the normalized cross-correlation function are shown in Table 4.

Table 3. Time delays at peak of cross correlation of $130^{\circ}$ microphone signal and CIP1 combustor pressure signal, ms

\begin{tabular}{lllllll}
\hline \hline Engine power & No & Low-pass & Low-pass & Low-pass & Low-pass & Low-pass \\
level & filter & $400 \mathrm{~Hz}$ & $300 \mathrm{~Hz}$ & $200 \mathrm{~Hz}$ & $\approx 150 \mathrm{~Hz}$ & $100 \mathrm{~Hz}$ \\
\hline 48 percent & 90.18 & 90.07 & 90.33 & 90.76 & 91.34 & 92.06 \\
54 percent & 89.74 & 90.19 & 90.52 & 90.90 & 91.16 & 92.12 \\
60 percent & 90.13 & 90.07 & 90.38 & 90.71 & 90.85 & 91.46 \\
71 percent & 90.62 & 90.67 & 90.91 & 91.08 & 91.25 & 92.16 \\
\hline \hline
\end{tabular}

Table 4. Peak values of normalized cross-correlation function of $130^{\circ}$ microphone signal and CIP1 combustor pressure signal

\begin{tabular}{lllllll}
\hline \hline Engine power & $\begin{array}{l}\text { No } \\
\text { level }\end{array}$ & Low-pass & Low-pass & Low-pass & Low-pass & $\begin{array}{l}\text { Low-pass } \\
\text { filter }\end{array}$ \\
$400 \mathrm{~Hz}$ & $300 \mathrm{~Hz}$ & $200 \mathrm{~Hz}$ & $\approx 150 \mathrm{~Hz}$ & $100 \mathrm{~Hz}$ \\
\hline 48 percent & 0.026 & 0.237 & 0.284 & 0.337 & 0.379 & 0.429 \\
54 percent & 0.023 & 0.188 & 0.220 & 0.228 & 0.182 & 0.182 \\
60 percent & 0.016 & 0.177 & 0.215 & 0.228 & 0.178 & 0.169 \\
71 percent & 0.013 & 0.132 & 0.162 & 0.154 & 0.109 & 0.098 \\
\hline \hline
\end{tabular}




\section{B. Tones and the coherence threshold}

The method of aligned and unaligned coherence presented by Miles $^{46}$ is extended in this report to include cross-correlation functions. Aligned and unaligned cross-correlation and coherence functions are calculated. The unaligned cross-correlation and coherence functions are calculated using signals unaligned by 2.74 sample segment lengths, $\left(D_{T}=2.74 T_{d}=1.37 \mathrm{~s}\right)$.

Figure 11 shows the unaligned coherence function between the microphone at $130^{\circ}$ and the combustor pressure sensor, CIP1, at four power settings. The presence of tones is clearly observable. The signal processing is done using signals low-pass filtered at $400 \mathrm{~Hz}$, unaligned by 2.74 sample segment lengths $\left(D_{T}=2.74 T_{d}=1.37 \mathrm{~s}\right)$ to obtain measured coherence noise floor and to observe tones. The measured noise floor and the statistical noise floor are in good agreement. Tones are tabulated in Table 5 . The tone at 18 $\mathrm{Hz}$ occurred at all power settings.

Figure 12 shows the corresponding unaligned cross-correlation functions. The tone at $18 \mathrm{~Hz}$ has a period of $T=1 / 18=55 \mathrm{~ms}$. This wave structure is shown in Fig. 12 at each power setting. This wave is modulated by waves with periods of 2 to $10 \mathrm{~ms}$.

Table 5. Tones identified with

unaligned coherence (see Fig. 11).

\begin{tabular}{|l|l|l|}
\hline $\begin{array}{l}\text { Engine power } \\
\text { level }\end{array}$ & $\begin{array}{l}\text { Tone } \\
\text { frequency, Hz }\end{array}$ & $\begin{array}{l}\text { Coherence } \\
\text { magnitude }\end{array}$ \\
\hline \hline 48 percent & 18 & 0.2228 \\
54 percent & 354 & 0.15 \\
& 18 & 0.17629 \\
60 percent & 86 & 0.0574 \\
& 18 & 0.2206 \\
& 96 & 0.103 \\
71 percent & 380 & 0.16848 \\
& 18 & 0785 \\
& 398 & 0.2223 \\
\hline
\end{tabular}

\section{Filtering to remove frequencies greater than $400 \mathrm{~Hz}$}

Miles $(2008)^{1}$ has shown that the cross-spectrum phase angle of unfiltered signals can be used to separate direct and indirect combustion noise. In this section, it is shown that the method works for the signals that are low-pass filtered at $400 \mathrm{~Hz}$. Only the results at 48 percent of maximum power are shown.

Figure 13 shows that the phase angle in the $200-400 \mathrm{~Hz}$ region (direct noise source region) is flat if a $86.98 \mathrm{~ms}$ time delay is removed. Figure 14 shows that the phase angle in the $0-200 \mathrm{~Hz}$ region (indirect noise source region) is flat if a $90.03 \mathrm{~ms}$ time delay is removed. This yields a $3.05 \mathrm{~ms}$ time delay between the direct combustion noise acoustic signal and the indirect combustion noise acoustic signal.

Figures 13 and 14 show the ripple in the cross-correlation function (panel a) corresponds to the peak in the coherence function near $36 \mathrm{~Hz}$ (panel $b$ ). The broadband $36 \mathrm{~Hz}$ peak in panel $\mathrm{b}$ has a coherence value of 0.62 . The broadband $36 \mathrm{~Hz}$ tone might be an entropy wave feedback tone. This broadband $36 \mathrm{~Hz}$ tone does not appear in the unaligned coherence.

The $18 \mathrm{~Hz}$ and the $354 \mathrm{~Hz}$ tones identified using the unaligned coherence (Fig. 11) are also present in the aligned coherence (Figs. $13 \mathrm{~b}$ and $14 \mathrm{~b}$ ). The $18 \mathrm{~Hz}$ tone has a coherence value of 0.27 . The $354 \mathrm{~Hz}$ tone might be related to a compressor disk tone.

Ignoring the $36 \mathrm{~Hz}$ tone, the coherence plots in Figs. $13 \mathrm{~b}$ and $14 \mathrm{~b}$ indicate that the combustion noise peaks between 100 and $200 \mathrm{~Hz}$. The coherent output power plots shown in Figs. $13 \mathrm{~d}$ and $14 \mathrm{~d}$ also indicate that the combustion noise peaks between 100 and $200 \mathrm{~Hz}$. Similar results were obtained at engine power settings of 54,60 , and 71 percent of the maximum power setting. 


\section{Filtering to remove frequencies greater than $150 \mathrm{~Hz}$}

For the $150 \mathrm{~Hz}$ low-pass filtered signal peak values of the cross-correlation function are shown in Table 3 and occur near $91 \mathrm{~ms}$. These peak values are significantly different than the values obtained using the unfiltered signals and the signals low-pass filtered at $400 \mathrm{~Hz}$ which are closer to $90 \mathrm{~ms}$.

Figure $15 \mathrm{c}$ shows the phase angle in the $200-400 \mathrm{~Hz}$ region (direct noise source region) is flat if a 86.98 time delay is removed. Figure $16 \mathrm{c}$ shows the phase angle in the $0-200 \mathrm{~Hz}$ region (indirect noise source region) is flat if a $90.03 \mathrm{~ms}$ time delay is removed. This yields a $3.05 \mathrm{~ms}$ time delay between the direct combustion noise acoustic signal and the indirect combustion noise acoustic signal.

Figures 15 and 16 show the ripple in the cross-correlation function (panel a) corresponding to the peak in the aligned coherence function near $36 \mathrm{~Hz}$ (panel b). The $18 \mathrm{~Hz}$ tone identified using the unaligned coherence is also present in the aligned coherence.

Ignoring the tone, the coherence plots in Figs. 15b and 16b again indicate that the combustion noise peaks between 100 and $200 \mathrm{~Hz}$. The coherent output power plots shown in Figs. 15d and 16d also indicate that the combustion noise peaks between 100 and $200 \mathrm{~Hz}$. Similar results were obtained at engine power settings of 54,60, and 71 percent of the maximum power setting.

\section{Discussion}

\section{A. Dependent Source Separation}

An interpretation of the results shown in Table 3 can be made by plotting the time delays at the peak of the cross correlation of the filtered $130^{\circ}$ microphone signal and the CIP1 combustor sensor signal. Let

$$
\left.\Delta \tau\left(f_{L}\right)\right|_{\text {peak }}=\left.\tau\left(f_{L}\right)\right|_{\text {peak }}-90 \mathrm{~ms}
$$

where the plotting values of the time delays are calculated relative to $90 \mathrm{~ms}$. This plot is shown in Fig. 17. As the low-pass filter design cutoff frequency, $f_{L}$, is reduced, the time delays tend to increase because a decreasing amount of direct combustion noise is present. The reference value of $90 \mathrm{~ms}$ was selected since the results of using no filter and a $400 \mathrm{~Hz}$ filter are near this value as is propagation time delay shown in Table

1. These results show low-pass filtering can be used to separate this type of dependent source.

\section{B. Identification of combustion noise}

The use of a sequence of low-pass filters to study the cross-correlation of the noise from the CIP1 sensor and the $130^{\circ}$ far-field microphone also show that filtering can increase the correlation function significantly. The peak values of the correlation function shown in table 4 are plotted in Fig. 18. A low-pass filter in the range of $200-300 \mathrm{~Hz}$ works well. When a tone is present, as it is for the 48 percent of maximum power setting, the correlation is increasing because the tone becomes increasingly dominant.

\section{Identification of periodic components}

For an engine power setting of 48 percent maximum power, a strong periodic signal is revealed by the cross-correlation function calculated using the far-field microphone and the combustor sensor. This signal appears with or without filtering as shown in Fig. 3. The coherence shown in part (b) of Figs. 13-16 and the coherent output power shown in part (d) of Figs. 13-16 also indicate the presence of this tone. The cross-correlation function indicates the tone has period of about $T=0.025 \mathrm{~s}$ which means the frequency is about $f=1 / T=40 \mathrm{~Hz}$ as shown. This tone corresponds to the $36 \mathrm{~Hz}$ peak observable in the aligned coherence plots shown in panel b of Figs. 13-16. The signal may be due to a feedback mechanism. At a higher power setting, it is not observed.

A somewhat similar cross-correlation function was shown in Fig. 13 of a study by Reshotko and Karchmer $^{25}$ of combustion noise from a Pratt \& Whitney JT15D at 40 percent maximum power. The crosscorrelation function had a period of about $T=0.07 \mathrm{~s}$ which indicates a frequency of about $f=1 / T=142 \mathrm{~Hz}$. This corresponded to the peak of the largest coherence function shown in Fig. 14 of the paper by Reshotko and Karchmer. ${ }^{25}$ 
The cross-correlation function identifies periodic components in a manner that clearly indicates their significance.

\section{Source separation}

The cross-correlation function of white noise and white noise displaced by $86.98 \mathrm{~ms}$ as shown in Fig. 2 produces a spike at $86.98 \mathrm{~ms}$. Close examination shows some structure to the function with features that vary positively and negatively by $10^{-4}$ and $10^{-5}$. For filtered white noise, the cross-correlation function is no longer sharp as shown in Fig. 2. The resolution has been decreased by filtering. The presence of tones creates new issues as shown in Fig. 3.

The plots shown in Figs. 3-9 show that two separate peaks cannot always be observed in the crosscorrelation function. Consequently, source separation of direct and indirect combustion noise cannot always be reliably determined directly from the cross-correlation. However, a time delay was identified in all cases by the cross-correlation function, clearly indicating the combustor as the source of the noise. In addition, using different filter cutoff frequencies clearly separates the sources. The cross-correlation function peaks at a time delay depending on the blend of indirect and direct combustion noise. The unfiltered signals and the signals low-pass filtered at $400 \mathrm{~Hz}$ have time delays that peak at about $90 \mathrm{~ms}$. The signals low-pass filtered at $150 \mathrm{~Hz}$ have time delays that peak at about $91 \mathrm{~ms}$.

These results suggest that previous discussions of the measurements of the cross-correlation between the combustor and a far-field microphone by Karchmer and Reshotko, ${ }^{23}$ Karchmer, ${ }^{24}$ Reshotko and Karchmer, ${ }^{25}$ and Mathews et al. $^{26}$ did not consider that the measured time delay using filtered signals caused by a blend of signals from direct and indirect combustion noise. Consequently, these previous measurements might be due more to indirect combustion noise than direct combustion noise, because filtered cross-correlaton functions are used by Karchmer and Reshotko, ${ }^{23}$ Karchmer, ${ }^{24}$ Reshotko and Karchmer, ${ }^{25}$ and Mathews et al. ${ }^{26}$ and some of the direct combustion noise may have been removed by filtering.

The cross-correlation function and coherence function methods provide a procedure to detect the presence of coherent indirect and direct combustion noise when both are present. However, the inherent smearing because of filtering renders the determination of the relative contribution of indirect and direct combustion noise to the total combustion noise difficult.

\section{E. Combustor acoustic measurements}

The low-frequency acoustic cross spectrum and the acoustic cross-correlation function have been identified for a range of operating conditions. The circumferential acoustic combustor modes in the TECH977 engine are discussed by Royalty and Schuster. ${ }^{6}$ They found that most of the acoustic energy below $500 \mathrm{~Hz}$ is contained in the plane wave mode (mode order $=0$ ). The results presented correspond to the propagation of plane waves from the combustor to the far field.

\section{F. Limitations}

The presence of tones in the signals and the decrease in resolution of the cross-correlation function with the filtering prevented the cross-correlation function from identifying source separation of direct and indirect combustion noise by finding separate time delays for each. These limitations were overcome to some extent by using the low-pass filter approach. However, the presence of low-frequency tones in the filter band remains a problem.

The cross-spectrum phase angle approach identifies the indirect combustion noise propagation time to be of the order of $90 \mathrm{~ms}$, while the correlation function approach identifies the indirect combustion noise propagation time to be of the order of 91 to $92 \mathrm{~ms}$. The cross-spectrum phase angle approach identifies the direct combustion noise propagation time to be of the order of $87 \mathrm{~ms}$, while the correlation function approach identifies the direct combustion noise propagation speed to be less than $90 \mathrm{~ms}$.

The lowest cutoff frequency filter removes much of the random, broadband noise. However, this creates signals with a correlation function strongly influenced by the remaining tones. This makes it difficult to obtain a valid propagation time delay for the indirect combustion noise in the $0-200 \mathrm{~Hz}$ frequency band.

A $200-400 \mathrm{~Hz}$ bandpass filter was used in hopes of identifying a better time delay for the direct combustion noise in this frequency band. However, the resulting correlation function did not have a single 
identifiable peak. In place of the peak was a modulated waveform with many peaks that appeared in the 80-100 ms region with an envelope that had a single peak in the region. Discussing the use of sophisticated notch and bandpass filters to analyze this data is beyond the scope of this report.

The correlation function procedure currently supplies support for the idea that the indirect and direct core noise can be separated by the time delay due to entropy wave (hot spot) convection. However, the method for this data set does not produce the same result as that given by examination of the crossspectrum phase angle. In addition, it is more complicated to apply. The best part about the correlation function procedure is that it gives definite evidence that combustion noise is part of the far-field signal.

\section{G. Delay time consistency}

Table 3 shows the delay times measured are more dependent on the filtering than on the operating condition. This can be understood in general terms using information from papers on gas-turbine engine instability such as those in a volume edited by Lieuwen and Yang, ${ }^{36}$ with information on gas-turbine combustion as discussed for by Lefebvre, ${ }^{47}$ and with information presented by Hill and Peterson ${ }^{34}$ on the mechanics and thermodynamics of propulsion.

It is assumed that the delay time only depends on the difference between the travel time of the entropy to the turbine and the acoustic travel time to the turbine. From the turbine to the far field, the signals are acoustic and travel the same path to the far-field microphone. In calculating the noise produced by a hot spot, one might have to consider which blade produces the noise and the further propagation of a hot spot. These complications will be ignored.

The delay time can be estimated by

$$
\begin{aligned}
\Delta \tau & =\tau_{s}-\tau_{a} \\
& \approx L_{c} / v_{s}-L_{c} / c_{c} \\
& =\left(L_{c} / c_{c}\right)\left(1 / M_{c}-1\right) \\
& =\left(L_{c} / c_{c}\right)\left(1-M_{c}\right) / M_{c} \approx L_{c} / v_{s}
\end{aligned}
$$

where $M_{c}=v_{s} / c_{c}$ is the combustor Mach number, and $c_{c}=\sqrt{\gamma^{\Re} T_{c} / W}$ is the local speed of sound in the combustor.

The difference in the measured time delay for the direct combustion noise and the indirect combustion noise, $\Delta \tau$, has been shown to be about $3 \mathrm{~ms}$, using the method based on the cross-spectrum phase angle. The use of the correlation function approach yielded a mixed value of $\Delta \tau$ of the order of 2 to $5 \mathrm{~ms}$. Reasonable values of $L_{c}, T_{c}$, and $M_{c}$ yield a value of 2 to $5 \mathrm{~ms}$ for $\Delta \tau$. However, this must be left as an exercise for the reader.

The interesting point about Eq. (7) is that the delay time is mainly established by the combustor flow velocity and combustor length. Consequently, whatever the actual combustor length and whatever the combustor Mach number is, over a range of engine operating conditions, the time delay measured by the cross-correlation function should be fairly constant.

\section{Concluding Remarks}

Unfiltered and low-pass filtered cross-correlation functions between a combustor pressure sensor and a far-field microphone at $130^{\circ}$ at the 54,60 , and 71 percent of maximum power settings showed a single time delay peak. However, at the 48 percent of maximum power setting a single or double peak was observed depending on the low-pass filter cutoff frequency. The 48 percent operating condition cross-correlation functions showed a double peak when using signals unfiltered and filtered with cutoff frequencies of 400 , 300 , and $200 \mathrm{~Hz}$. For the unfiltered cross-correlation and the cross-correlation filtered using a $400 \mathrm{~Hz}$ cutoff frequency, at each power setting the largest peak is at an acoustic time delay near $90 \mathrm{~ms}$. For the double peak case at the 48 percent operating condition, the second peak is near $95 \mathrm{~ms}$. This indicates the left side of the double peak or single peak is due to direct combustion noise, which travels at acoustic speeds over its total path length; the right side of the double peak or single peak is due to indirect combustion noise.

Low-pass filtering with a $100 \mathrm{~Hz}$ cutoff frequency to remove a large amount of the direct combustion noise leaves the indirect combustion noise which has approximately a $92 \mathrm{~ms}$ time delay. This time delay is 
longer than the time delay observed with no filtering or low-pass filtering at $400 \mathrm{~Hz}$, which produced a time delay near $90 \mathrm{~ms}$. This shows some of the direct combustion noise, which is always traveling at the speed of sound, has been removed, leaving the indirect combustion noise which spends time moving convectively in the combustor at a much lower velocity than the speed of sound. As a consequence of removing part of the combustion noise that travels fastest, the delay time of the combustion noise remaining in the signal is greater. The cross-correlation function, when used with low-pass filtering, is very useful in separating the indirect and direct combustion noise source in this system.

The method of aligned and unaligned cross-correlation and coherence validated the statistical coherence threshold by determining by measurement the coherence of two measured time series. After delaying one of them for a time delay greater than the segment or block length used in the periodogram averaging, the coherence threshold is found. The use of the unaligned coherence removes the random noise coherence, leaving the coherence of any periodic process and the noise floor. In addition, the unaligned cross-correlation function was calculated to view the remaining periodic signals in the time domain.

Coherence analysis using the cross-spectrum phase angle method separates direct and indirect combustion noise using filtered or unfiltered signals. This is done by an examination of the effect that removal of different time delays has on the phase angle of the cross-spectrum calculated using the combustor pressure sensor signal and a far-field microphone signal. For the cross-spectrum between a combustor pressure sensor and a far-field microphone at $130^{\circ}$, this method indicated the direct signal had a time delay of $87 \mathrm{~ms}$, and the indirect signal had a time delay of $90 \mathrm{~ms}$. No explanation is available for this discrepancy between the two methods. However, the time difference for either method ranges from 2 to $5 \mathrm{~ms}$. This is the expected time range based on available information for combustor lengths and convective flow velocities. 


\section{References}

${ }^{1}$ Miles, J. H., "Spectral Separation of the Turbofan Engine Coherent Combustion Noise Component," AIAA-2008-50, January 2008, NASA TM-215157-0.

${ }^{2}$ Miles, J. H., "Time Delay Analysis of Turbofan Engine Direct and Indirect Combustion Noise Sources," Journal of Propulsion and Power, Vol. 25 No. 1, January-February 2009, pp. 218-217.

${ }^{3}$ Mendoza, J. M., Nance, D. K., and Ahuja, K. K., "Source Separation from Multiple Microphone Measurements in the Far Field of a Full Scale Aero Engine," Tech. Rep. AIAA-2008-2809, AIAA, 2008.

${ }^{4}$ Weir, D. S. and Mendoza, J. M., "Baseline Noise Measurements from the Engine Validation of Noise and Emissions Reduction Technology Program," Tech. Rep. AIAA-2008-2807, AIAA, 2008. AIAA, 2008.

${ }^{5}$ Schuster, B., "Statistical Considerations for Gas Turbine Engine Noise Measurements," Tech. Rep. AIAA-2008-2808,

${ }^{6}$ Royalty, C. M. and Schuster, B., "Noise fro a Turbofan Engine Without a Fan from the Engine Validation of Noise and Emission Reduction Technology (EVNERT) Program," Tech. Rep. AIAA-2008-2810, AIAA, 2008.

${ }^{7}$ Dougherty, R. P. and Mendoza, J. M., "Nacell In-duct Beamforming using Modal Steering Vectors," Tech. Rep. AIAA-2008-2812, AIAA, 2008.

${ }^{8}$ Engine Validation of Noise \& Emission Reduction Technology Phase 1, edited by D. S. Weir, NASA, May 2008, NASA/CR-2008-215225, Honeywell Report No 21-13843A.

${ }^{9}$ Pickett, G. F., "Core Engine Noise Due to Temperature Fluctuating Through Turbine Blade Rows," Tech. Rep. AIAA-75-528, AIAA, 1975 .

${ }^{10}$ Cumpsty, N. A. and Marble, F. E., "The Interaction of Entropy Fluctuations With Turbine Blade Rows; A Mechanism of Turbojet Noise." Proc. R. Soc. Lond. A., Vol. 357, 1977, pp. 323-344.

${ }^{11}$ Cumpsty, N. A. and Marble, F., "Core Noise from Gas Turbine Exhausts," Journal of Sound and Vibration, Vol. 54 No. 2, 1977, pp. 297-309.

${ }^{12}$ Cumpsty, N. A., "Jet Engine Combustion Noise: Pressure, Entropy and Vorticity Perturbations Produced by Unsteady Combustion or Heat Addition," Journal of Sound and Vibration, Vol. 66 No. 4, 1979, pp. 527-544.

${ }^{13}$ Gliebe, P., Mani, R., Shin, H., Mitchell, B., Ashford, G., Salamah, S., and Connell, S., "Acoustic Prediction Codes," Tech. Rep. NASA CR-2000-210244, R99AEB169, General Electric Aircraft Engines, August 2000.

${ }^{14}$ Miles, J. H., Wasserbauer, C. A., and Krejsa, E., "Cross Spectra Between Temperature and Pressure in a Constant Area Duct Downstream of a Combustor," AIAA-83-0762, NASA TM-83351, 1983.

${ }^{15}$ Bendat, J. S. and Piersol, A. G., Measurement and Analysis of Random Data, John Wiley \& Sons, 1966.

${ }^{16}$ Bendat, J. S. and Piersol, A. G., Random Data: Analysis and Measurement Procedures, John Wiley \& Sons, 1971. Sons, 1980 .

${ }^{17}$ Bendat, J. S. and Piersol, A. G., Engineering Applications of Correlation and Spectral Analysis, John Wiley \&

${ }^{18}$ Childers, D. and Durling, A., Digital Filtering and Signal Processing, West Publishing Company, 1975.

${ }^{19}$ Kay, S. M., Modern Spectral Estimation, Prentice Hall, 1987.

${ }^{20}$ Stearns, S. D. and David, R. A., Signal Processing Algorithms Using Fortran and C, Prentice Hall, Inc., 1993.

${ }^{21}$ Lee, Y. W., Cheatham Jr., T. P., and Wiesner, J. B., "Application of Correlation Analysis to the Detection of Periodic Signals in Noise," Proceedings of the I.R.E, Vol. 38 No. 10, 1950, pp. 1165-1171.

${ }^{22}$ White, P. H., "Cross Correlation in Structural Systems: Dispersion and Nondispersion Waves," The Journal of the Acoustic Society of America, Vol. 45 No. 5, 1969, pp. 1118-1128.

${ }^{23}$ Karchmer, A. M. and Reshotko, M., "Core Noise Source Diagnostics on a Turbofan Engine Using Correlation and Coherence Techniques," Tech. Rep. NASA TMX-73535, NASA, 1976.

${ }^{24}$ Karchmer, A. M., "Identification and Measurement of Combustion Noise From a Turbofan Engine Using Correlation and Coherence Techniques," Tech. Rep. NASA TM-73747, NASA, 1977, Doctor of Philosophy thesis E-9319.

${ }^{25}$ Reshotko, M. and Karchmer, A., "Core Noise Measurements From a Small, General Aviation Turbofan Engine," Tech. Rep. TM-81610, NASA, 1980, N81-11769.

${ }^{26}$ Mathews, D. C., Rekos, Jr., N. F., and Nagel, R. T., "Combustion Noise Investigation," Tech. Rep. FAA-RD-77-3, PWA-5478, FAA Report, 1977.

${ }^{27}$ Shivashankara, B. N., "Gas Turbine Core Noise Source Isolation by Internal-to-Far-Field Correlations," J. Aircraft, Vol. 15 No. 9, September 1978 , pp. 597-600. May 2008.

${ }^{28}$ Harper-Bourne, M., Moore, A., and Siller, H., "A Study of Large Aero-Engine Combustor Noise," AIAA-2008-2942,

${ }^{29}$ Schemel, C., Thiele, F., Bake, F., Lehmann, B., and Michel, U., "Sound Generation in the Outlet Section of Gas Turbine Combustion Chambers," AIAA-2004-2929, 2004.

${ }^{30}$ Richter, C., Panek, L., and Thiele, F. H., "On the Application of CAA-Methods for the Simulation of Indirect Combustion Noise," AIAA-2005-2919, May 2005.

${ }^{31}$ Bake, F., Michel, U., Roehle, I., Richter, C., Thiele, F., Liu, M., and Noll, B., "Indirect Combustion Noise Generation in Gas Turbines," AIAA-2005-2830, May 2005.

${ }^{32}$ Bake, F., Michel, U., and Roehle, I., "Investigation of Entropy Noise in Aero-Engine Combustors," Transactions of the ASME Journal of Engineering for Gas Turbines and Power, Vol. 129, April 2007, pp. 370-376.

${ }^{33}$ Bake, F., Kings, N., and Roehle, I., "Fundamental Mechanism of Entropy Noise in Aero-Engines: Experimental Investigation," Journal of Engineering for Gas Turbines and Power, Vol. 130 No. 1, January 2008, pp. 011202-1-011202-6.

${ }^{34}$ Hill, P. G. and Peterson, C. R., Mechanics and Thermodynamics of Propulsion: Second Edition, Addison-Wesley,

1992.

${ }^{35}$ Poinsot, T. and Veynante, D., Theoretical and Numerical Combustion: Second Edition, Edwards, 2005. 
${ }^{36}$ Lieuwen, T. C. and Yang, V., Combustion Instabilities in Gas Turbine Engines: Operational Experience, Fundamental Mechanisms, and Modeling, AIAA, 2005.

${ }^{37}$ Barrett, E. W. and Suomi, V. E., "Preliminary Report on Temperature Measurement by Sonic Mean," Journal of Meteorology, Vol. 6, August 1949, pp. 273-276.

${ }^{38} \mathrm{Cramer}, \mathrm{O}$., "The variation of the specific hear ratio and the speed of sound in air with temperature, pressure, humidity, and $\mathrm{CO}_{2}$ concentration," J. Acoust. Soc. Am., Vol. 93 No. 5, May 1993, pp. 2510-2516.

${ }^{39}$ Kormylo, J. J. and Jain, V. K., "Two-Pass Recursive Digital Filter with Zero Phase Shift," IEEE Transactions on Acoustics, Speech, and Signal Processing, Vol. 22 No. 5, October 1974, pp. 384-387.

${ }^{40}$ Hamming, R. W., Digital Filters Third Edition, Dover Publications, Mineola, New York, 1989, ISBN 0-486-65088-X, p. 252.

${ }^{41}$ Matsumoto, M. and Nishimura, T., "Mersenne Twister: A 623-Dimensionally Equidistributed Uniform PseudoRandom Number Generator," ACN Transactions on Modeling and Computer Simulation, Vol. 8 No. 1, January 1998, pp. 3-30.

${ }^{42}$ Carter, G. C., "Coherence and Time Delay Estimation," Proceedings of the IEEE, Vol. 75 No. 2, February 1987, pp. 236-255.

${ }^{43}$ Carter, G. C., "Receiver Operating Characteristics for a Linearly Thresholded Coherence Estimation Detector," IEEE Transactions on Acoustics, Speech, and Signal Processing, Vol. ASSP-25, February 1977, pp. 90-92.

${ }^{44}$ Halliday, D. M., Rosenberg, J. R., Amjad, A. M., Breeze, P., Conway, B. A., and Farmer, S. F., "A Framework for the Analysis of Mixed Time Series/Point Process Data-Theory and Application to the Study of Physiological Tremor, Single Motor Unit Discharges and Electromyograms," Progress in Biophysics and Molecular Biology, Vol. 64 No. 2, Elsevier, 1995, pp. 237-278.

${ }^{45}$ Brillinger, D. R., Time Series Data Analysis and Theory, Holden-Day, 1981.

${ }^{46}$ Miles, J. H., "Aligned and Unaligned Coherence: A New Diagnostic Tool," Tech. Rep. AIAA-2006-0010, AIAA, 2006, Presented at the 44th AIAA Aerospace Science Meeting, 9-12 Jan 2006 Reno Hilton Reno, Nevada, also NASA/TM2006-214112.

${ }^{47}$ Lefebvre, A. H., Gas Turbine Combustion, Taylor \& Francis, 1999. 


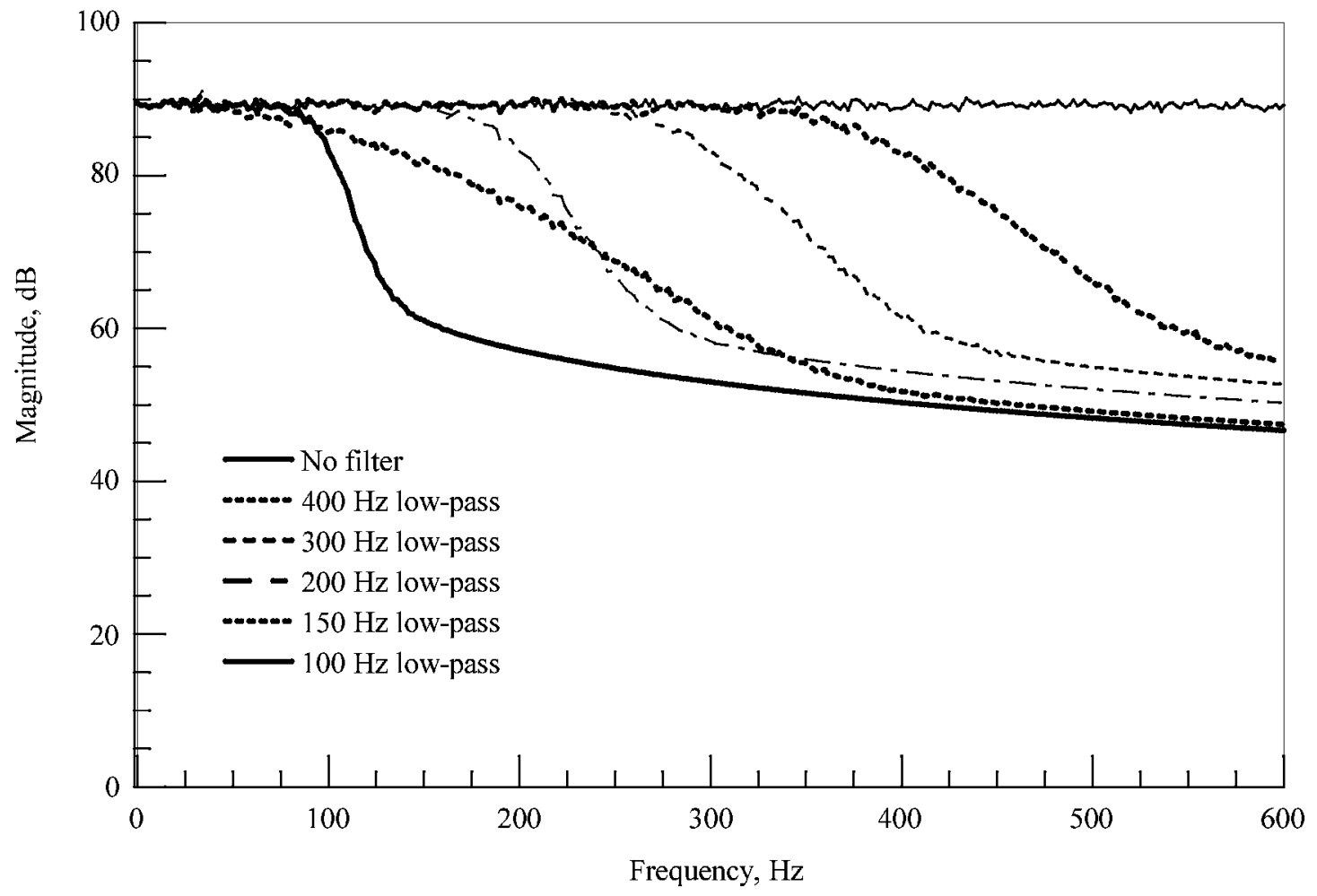

Figure 1. Low-pass filters acting on random noise. 


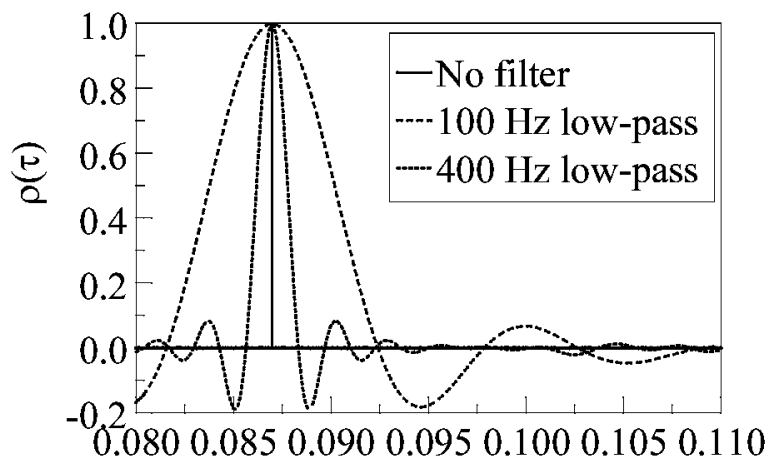

Time, $\tau, s$

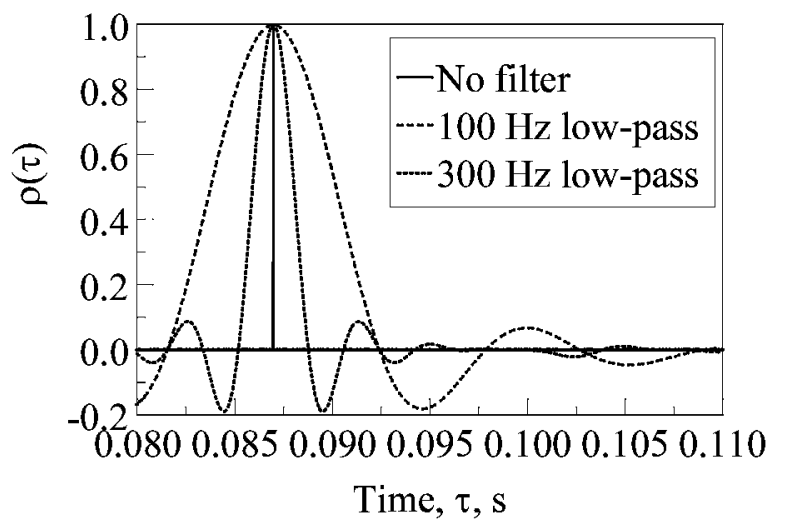

(b) 100 and $300 \mathrm{~Hz}$ low-pass filter.

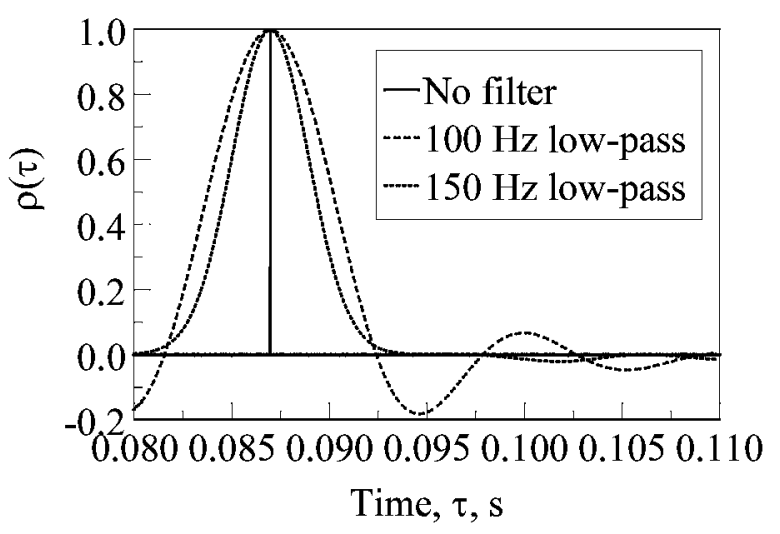

(d) 100 and $150 \mathrm{~Hz}$ low-pass filter.

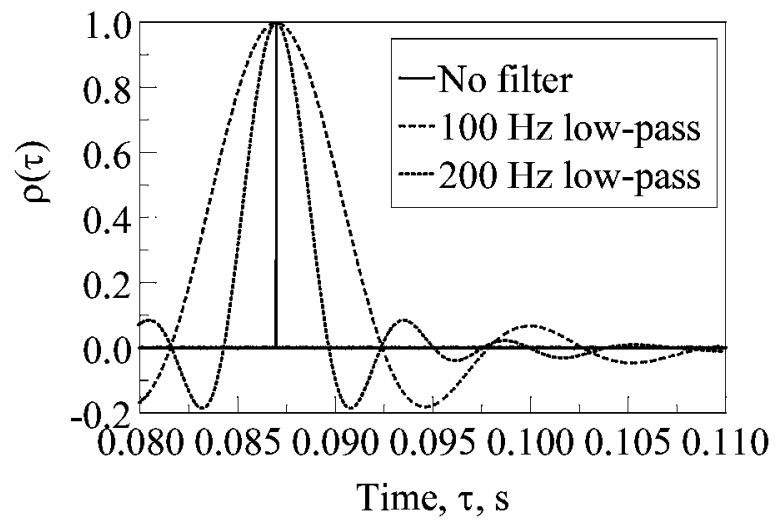

(c) 100 and $200 \mathrm{~Hz}$ low-pass filter.

Fure 2. Cross-correll
$700 / 65536=86.9751 \mathrm{~ms}$ 


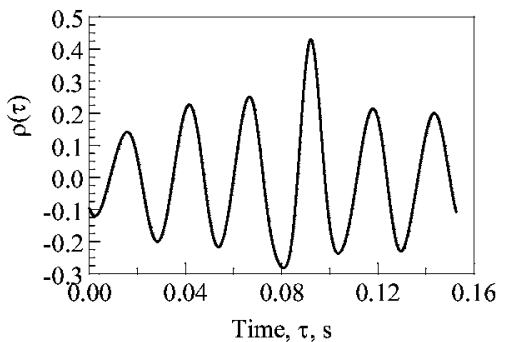

(a) $100 \mathrm{~Hz}$ low-pass filter.

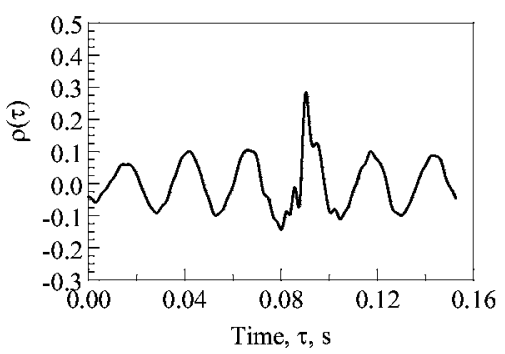

(d) $300 \mathrm{~Hz}$ low-pass filter.

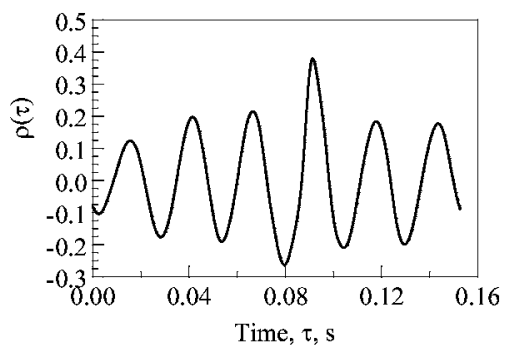

(b) $150 \mathrm{~Hz}$ low-pass filter.

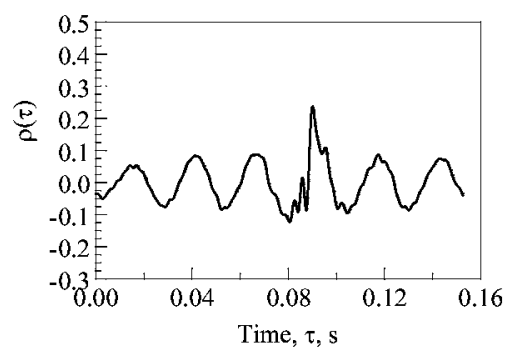

(e) $400 \mathrm{~Hz}$ low-pass filter.

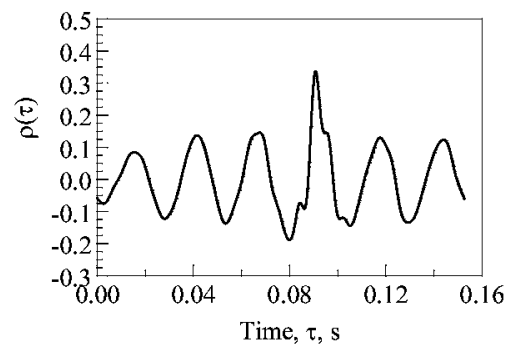

(c) $200 \mathrm{~Hz}$ low-pass filter.

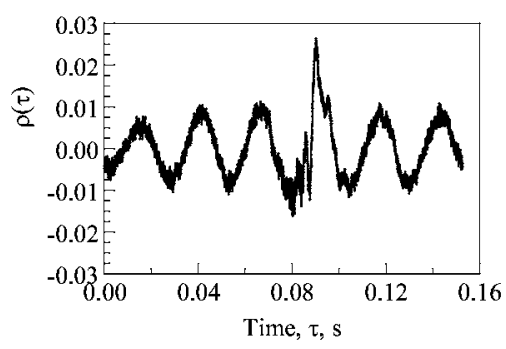

(f) No filter.

Figure 3. Normalized cross-correlation function for turbofan engine operating at a setting of 48 percent maximum power. 


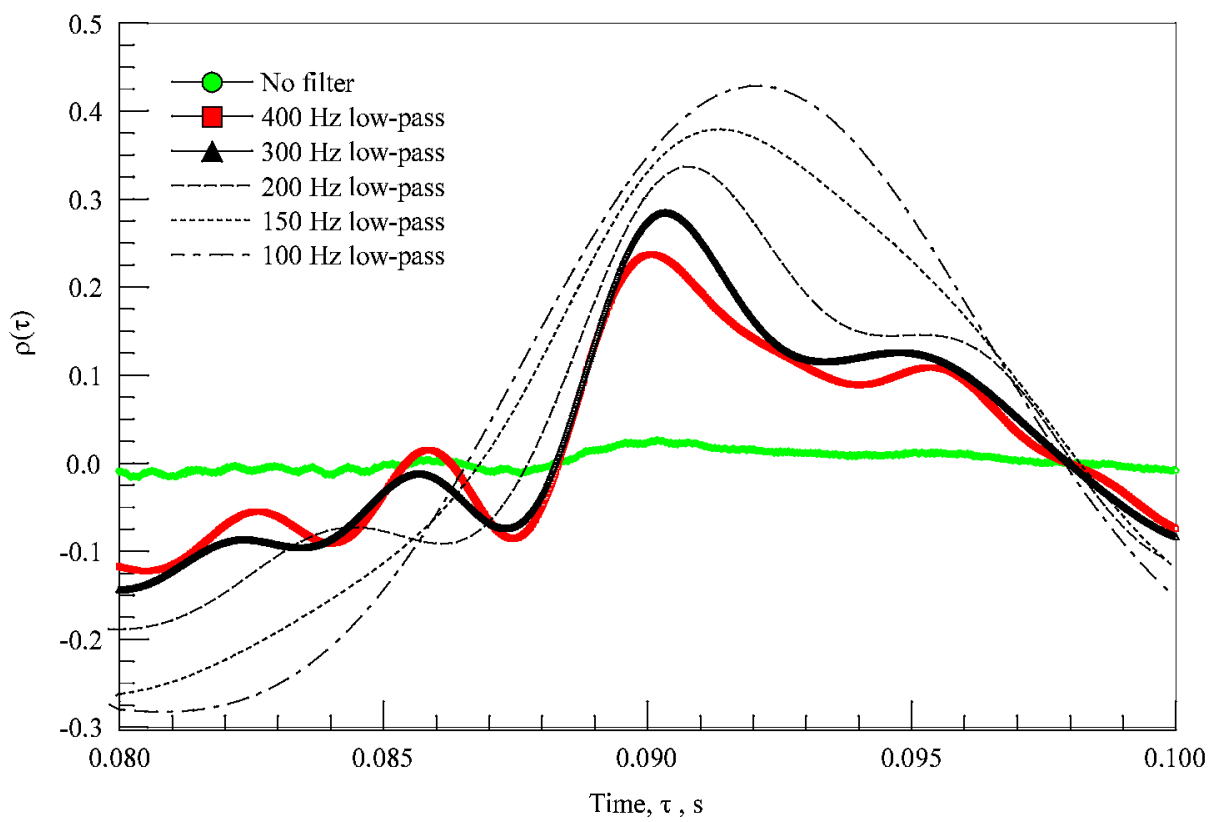

(a) $100-400 \mathrm{~Hz}$ low-pass filters.

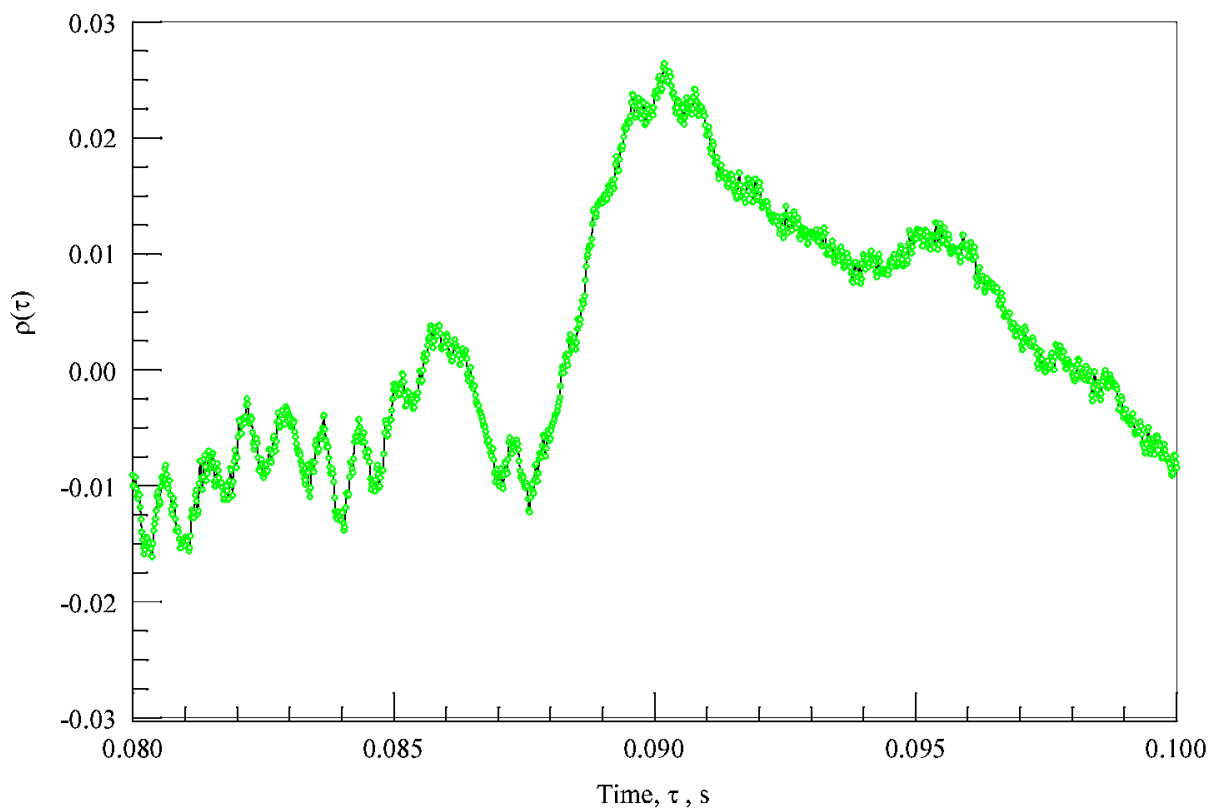

(b) No filter.

Figure 4. Normalized cross-correlation calculated at setting of 48 percent maximum power in region of peak values. 


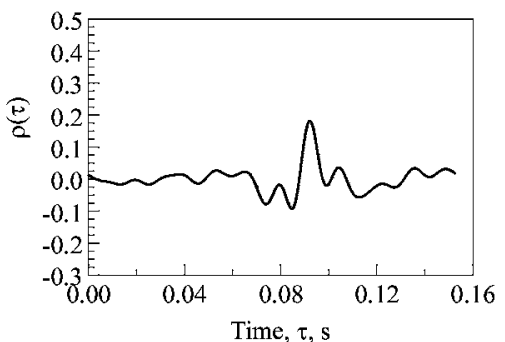

(a) $100 \mathrm{~Hz}$ low-pass Filter

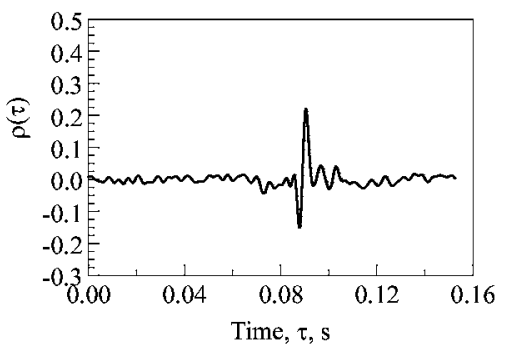

(d) $300 \mathrm{~Hz}$ low-pass Filter

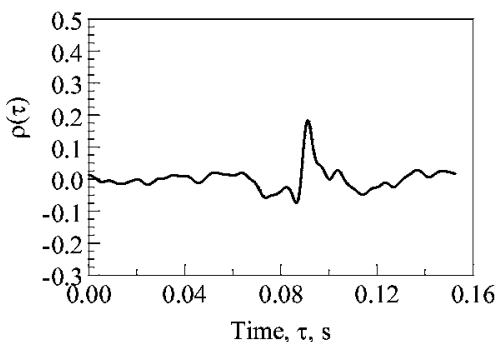

(b) $150 \mathrm{~Hz}$ low-pass Filter

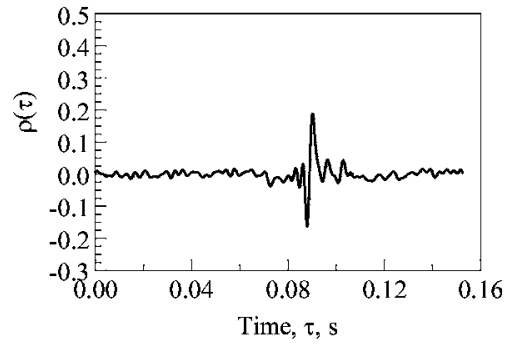

(e) $400 \mathrm{~Hz}$ low-pass Filter

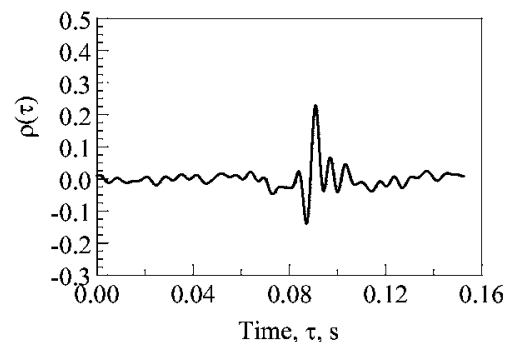

(c) $200 \mathrm{~Hz}$ low-pass Filter

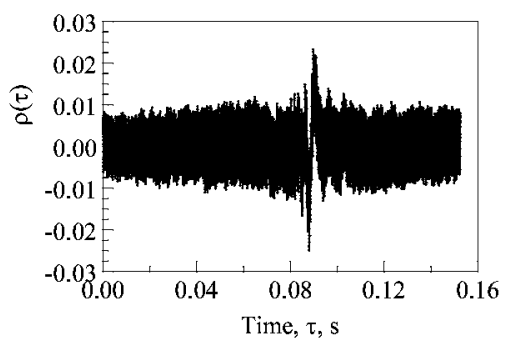

(f) No filter

Figure 5. Normalized cross-correlation function for turbofan engine operating at a setting of 54 percent maximum power. 


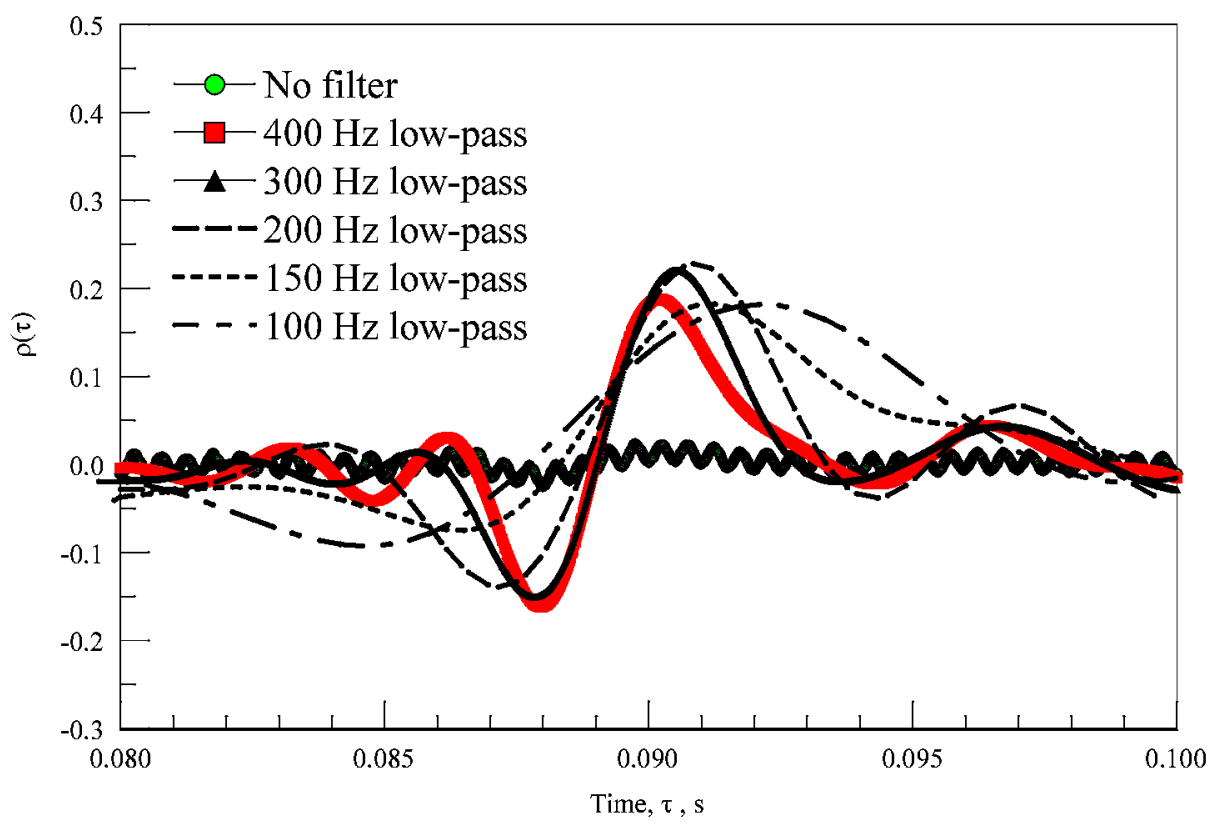

(a) $100-400 \mathrm{~Hz}$ low-pass filters

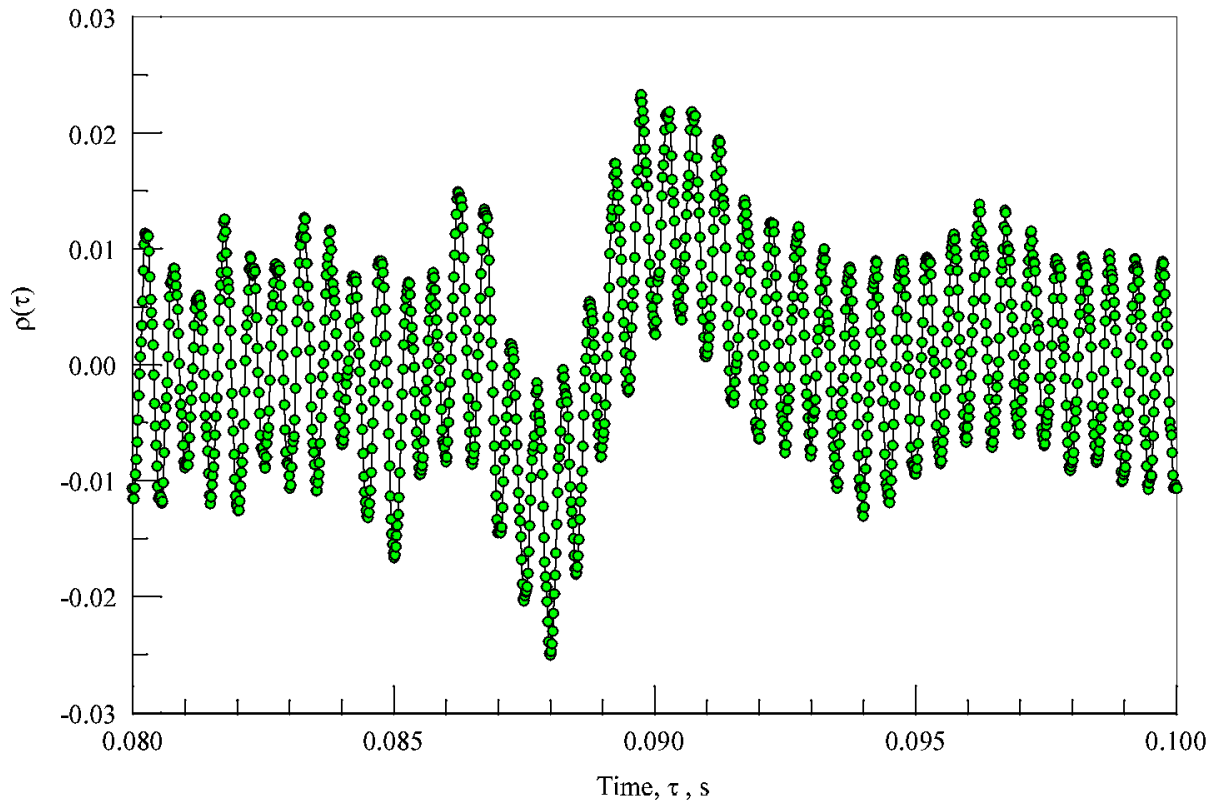

(b) No filter

Figure 6. Normalized cross-correlation calculated at a setting of 54 percent maximum power in region of peak values. 


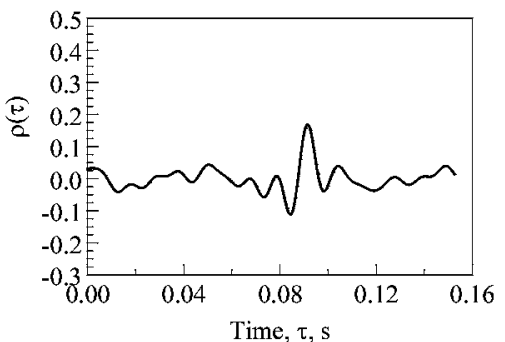

(a) $100 \mathrm{~Hz}$ low-pass Filter

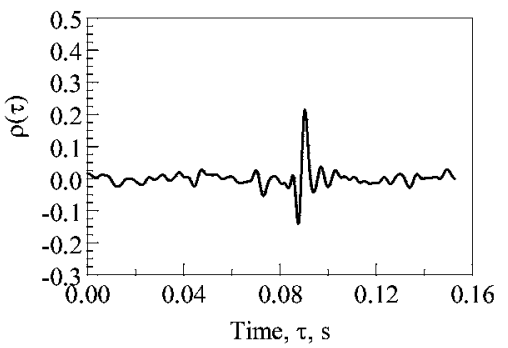

(d) $300 \mathrm{~Hz}$ low-pass Filter

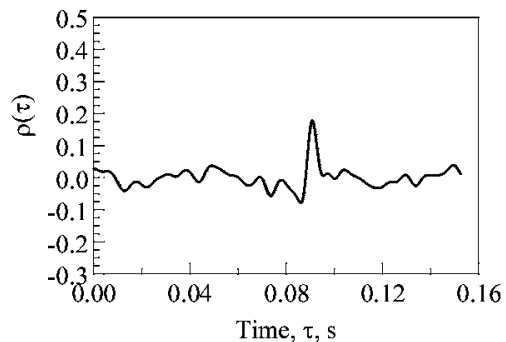

(b) $150 \mathrm{~Hz}$ low-pass Filter

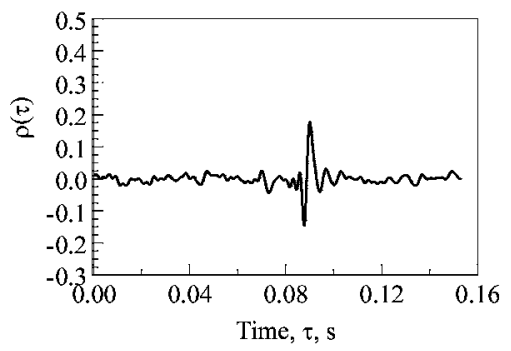

(e) $400 \mathrm{~Hz}$ low-pass Filter

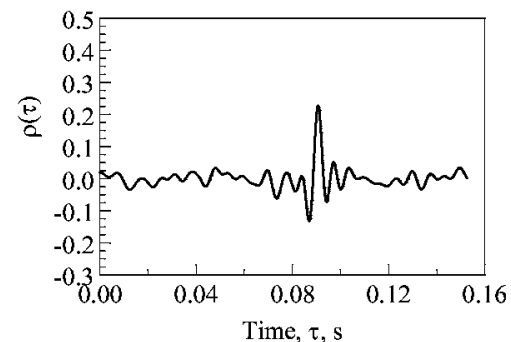

(c) $200 \mathrm{~Hz}$ low-pass Filter

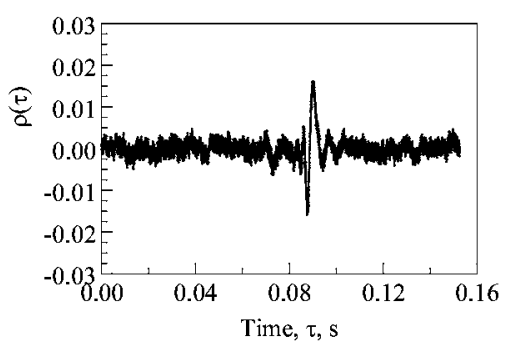

(f) No filter

Figure 7. Normalized cross-correlation function for turbofan engine operating at a setting of 60 percent maximum power. 


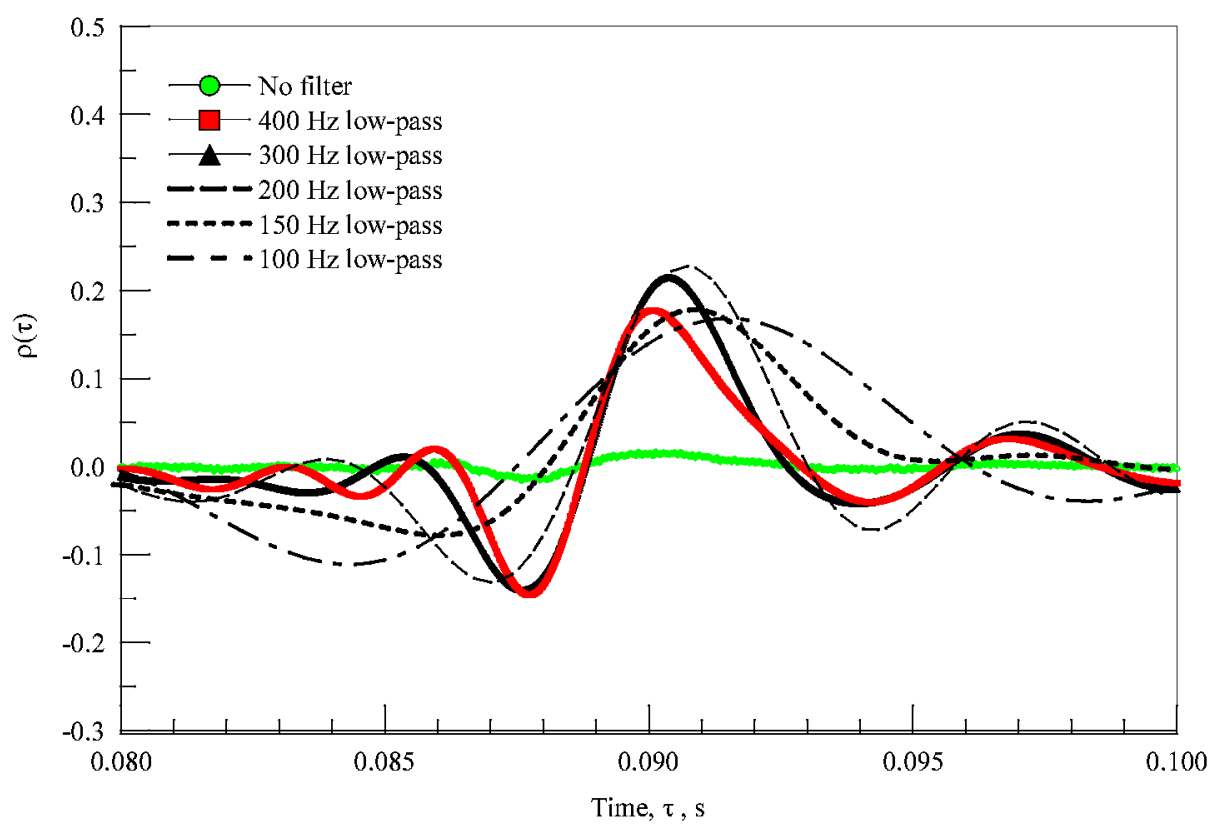

(a) $100-400 \mathrm{~Hz}$ low-pass filters

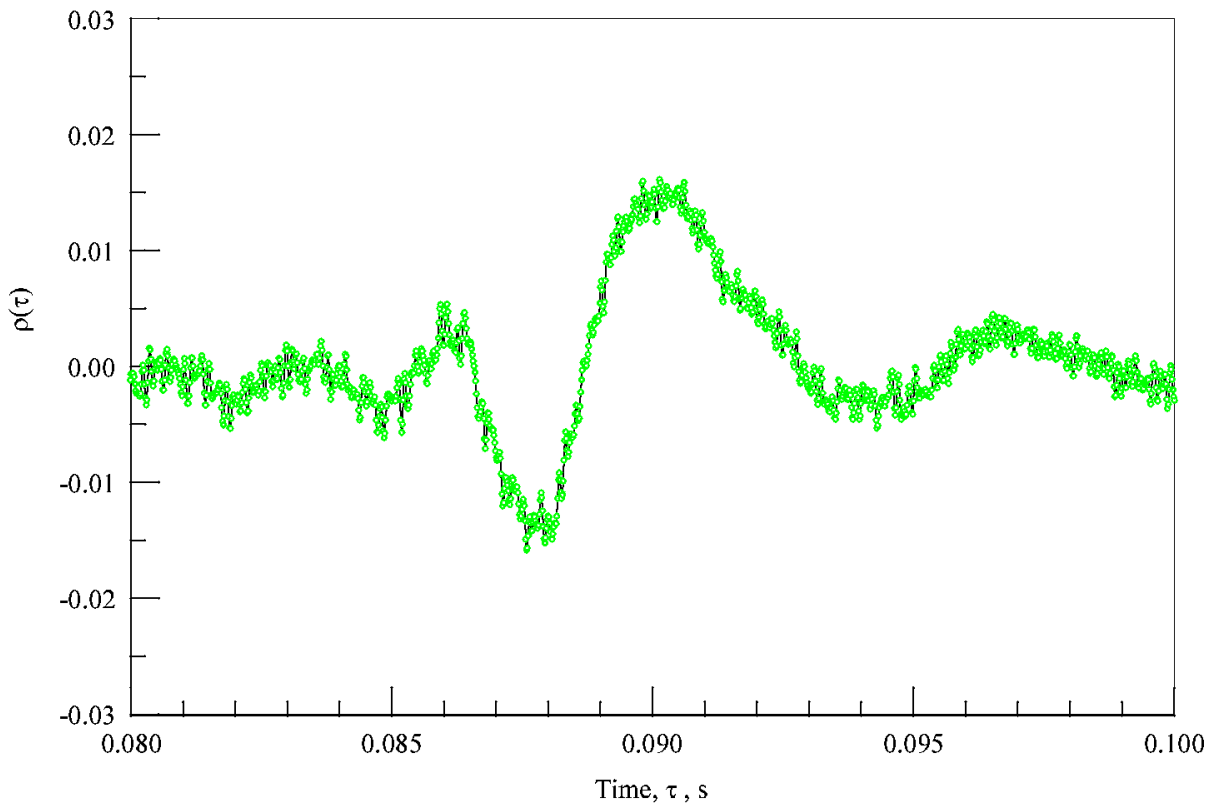

(b) No filter

Figure 8. Normalized cross-correlation calculated at setting of 60 percent maximum power in region of peak values. 


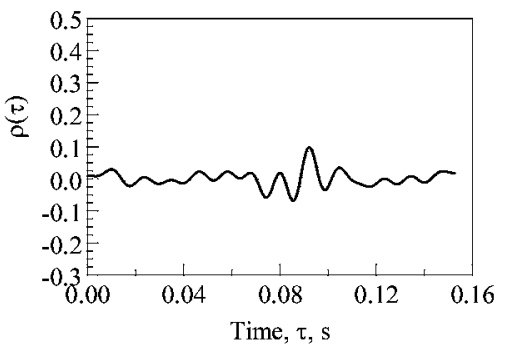

(a) $100 \mathrm{~Hz}$ low-pass filter

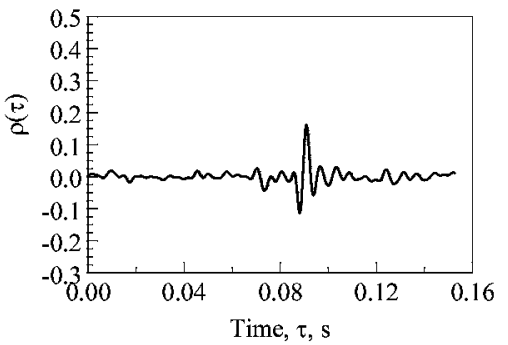

(d) $300 \mathrm{~Hz}$ low-pass filter

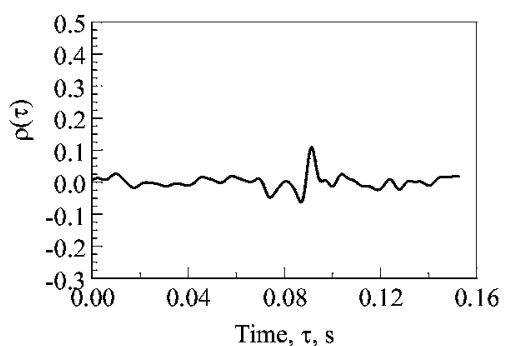

(b) $150 \mathrm{~Hz}$ low-pass filter

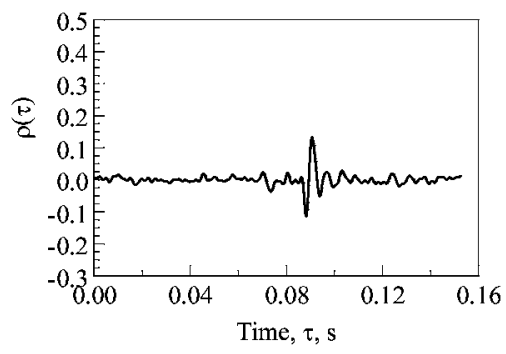

(e) $400 \mathrm{~Hz}$ low-pass filter

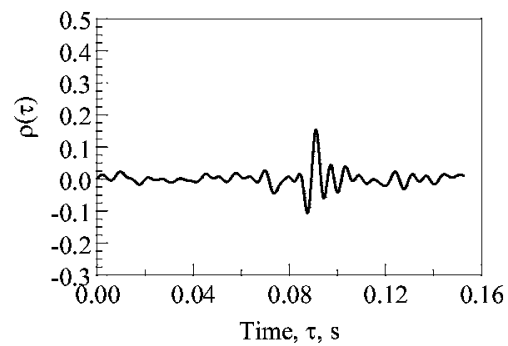

(c) $200 \mathrm{~Hz}$ low-pass filter



(f) No filter

Figure 9. Normalized cross-correlation function for turbofan engine operating at a setting of 71 percent maximum power. 


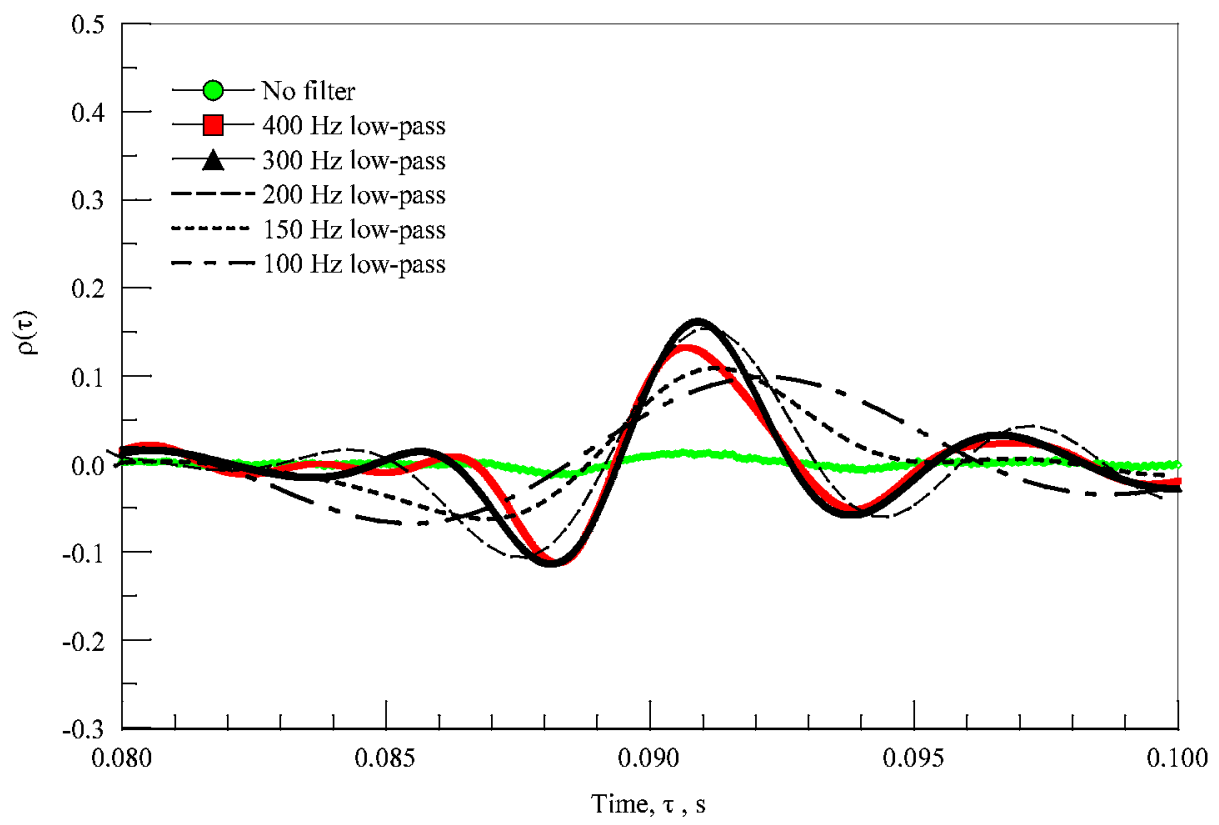

(a) $100-400 \mathrm{~Hz}$ low-pass filters

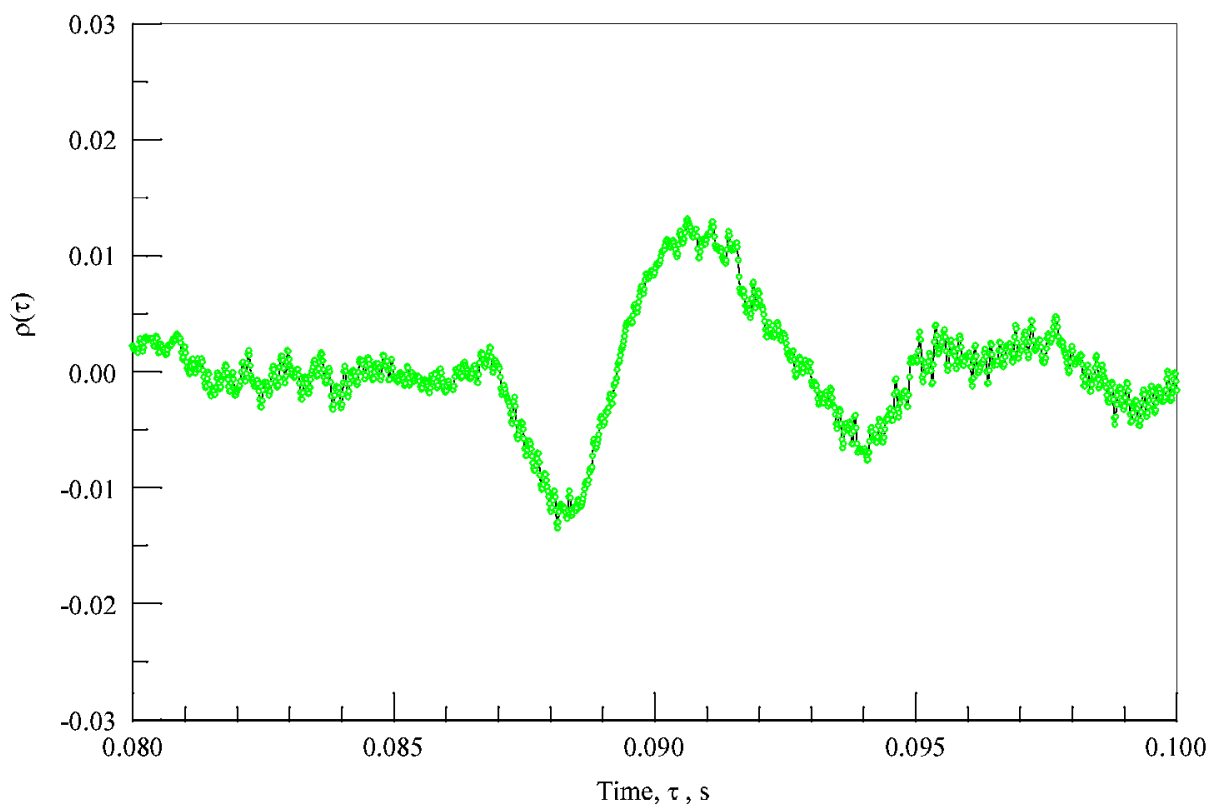

(b) No filter

Figure 10. Normalized cross-correlation calculated at setting of 71 percent maximum power in region of peak values. 


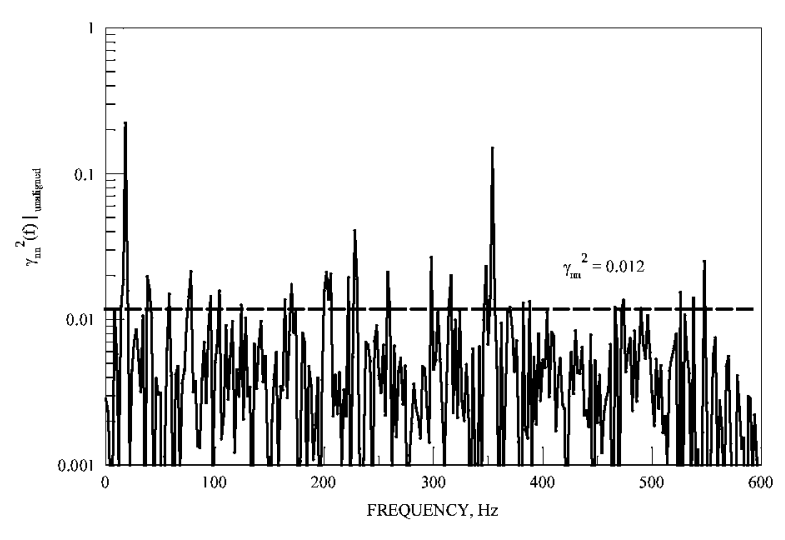

(a) 48 percent of maximum power.

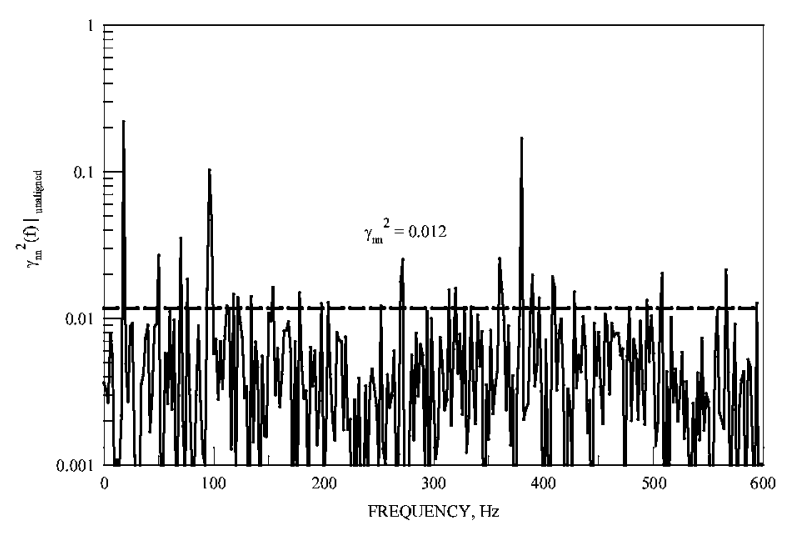

(c) 60 percent of maximum power.

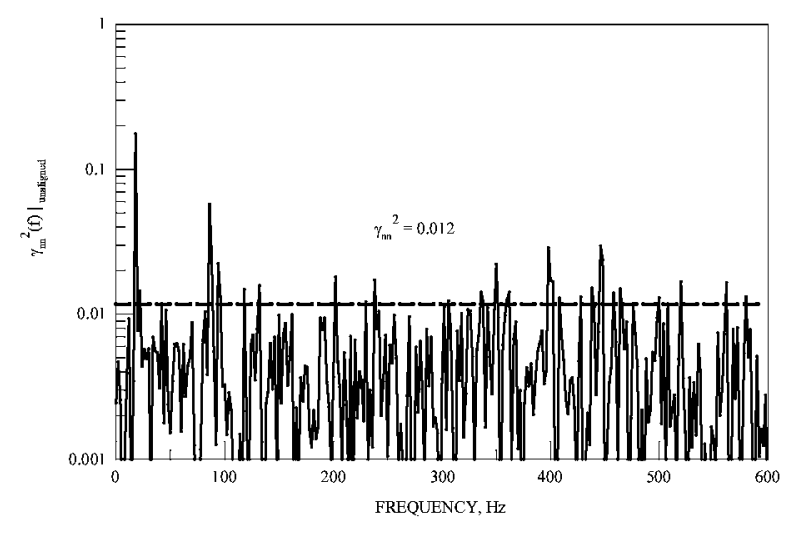

(b) 54 percent of maximum power.

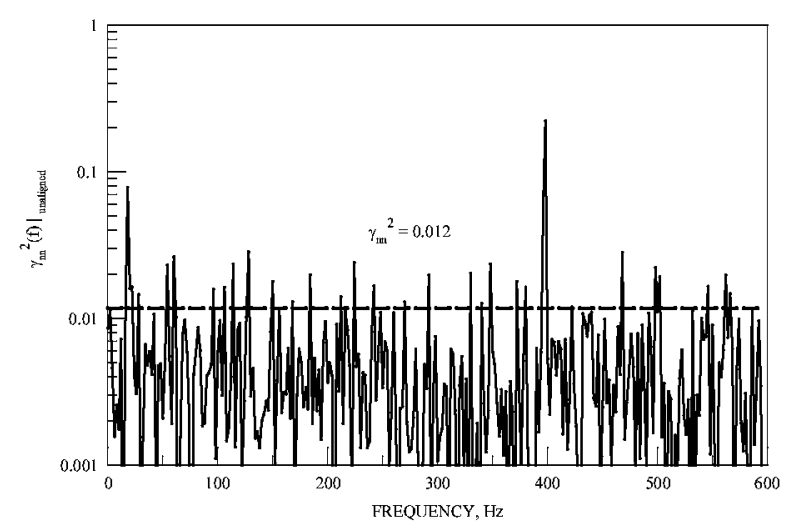

(d) 71 percent of maximum power.

Figure 11. Deliberately unaligned coherence between microphone at $130^{\circ}$ and CIP1 combustor pressure sensor using signals low-pass filtered at $400 \mathrm{~Hz}$ unaligned by 2.74 sample segment lengths, $\left(D_{T}=2.74 T_{d}=1.37 \mathrm{~s}\right)$ to measure coherence noise floor and to observe tones. 


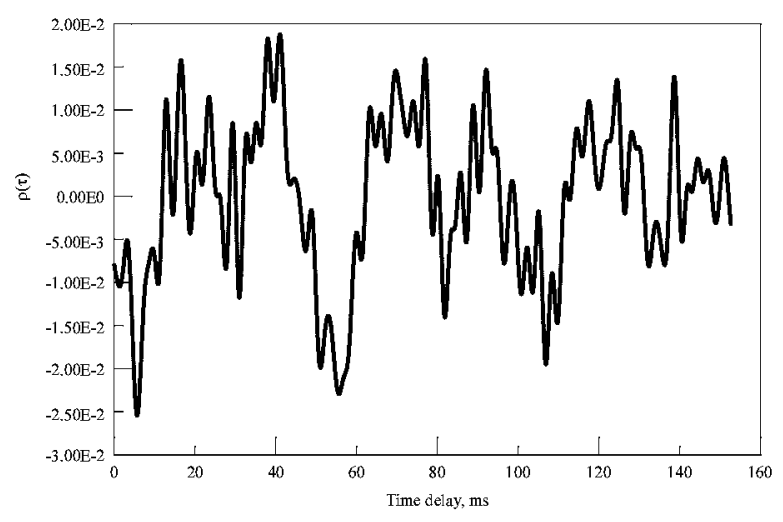

(a) 48 percent of maximum power.

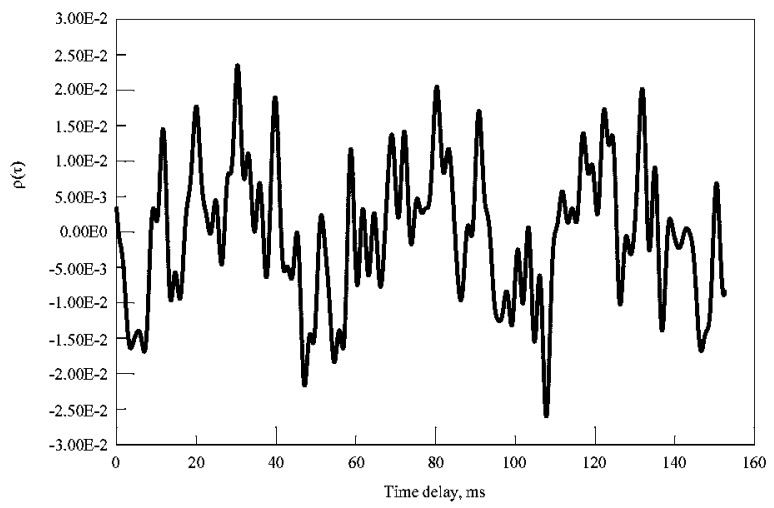

(c) 60 percent of maximum power.

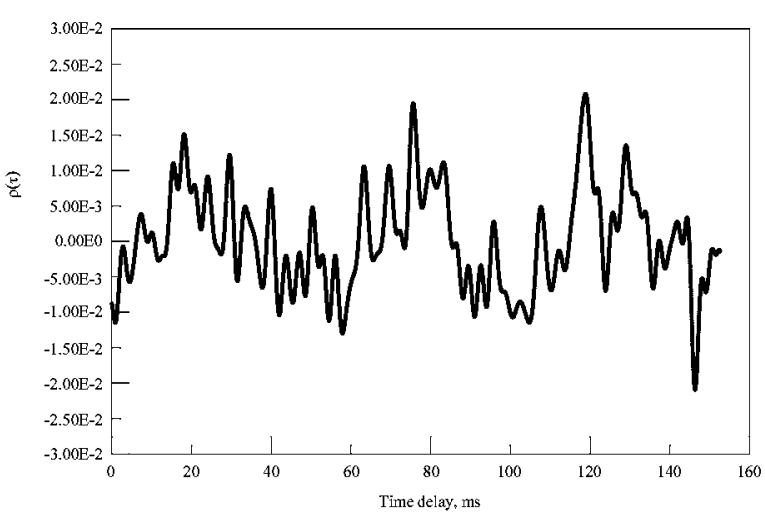

(b) 54 percent of maximum power.

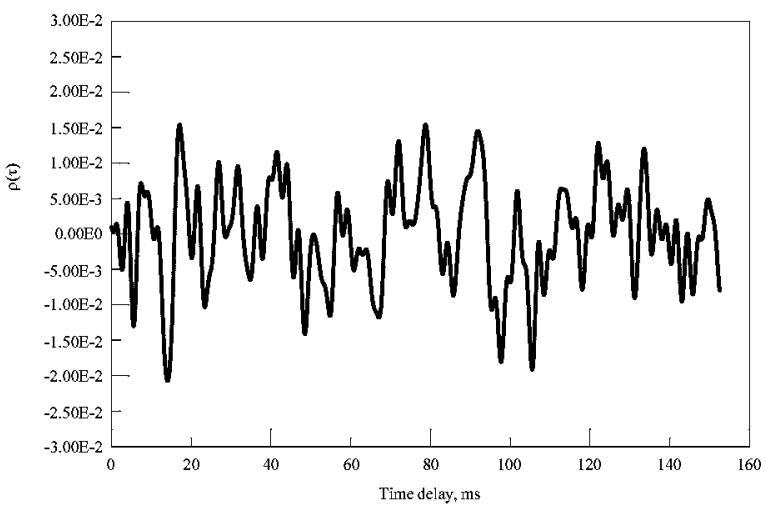

(d) 71 percent of maximum power.

Figure 12. Deliberately unaligned cross-correlation function between microphone at $130^{\circ}$ and CIP1 combustor pressure sensor. using signals low pass filtered at $400 \mathrm{~Hz}$ unaligned by 2.74 sample segment lengths $\left(D_{T}=\right.$ $\left.2.74 T_{d}=1.37 \mathrm{~s}\right)$ to observe tones. 


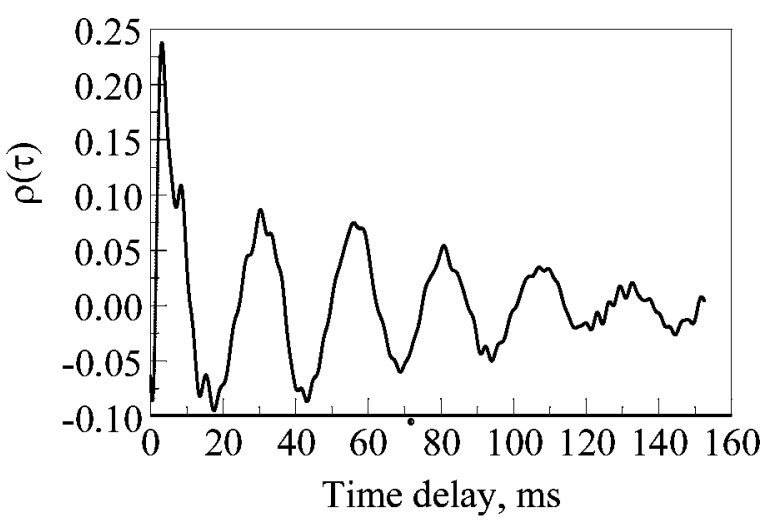

(a) Cross-correlation function between microphone at $130^{\circ}$ and CIP1 combustor pressure sensor.

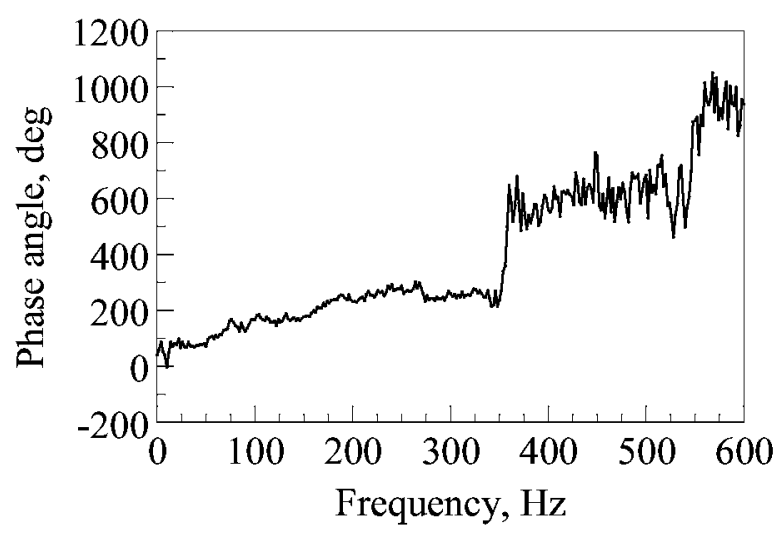

(c) Aligned unwrapped cross-spectrum phase angle between microphone at $130^{\circ}$ and CIP1 combustor pressure sensor.

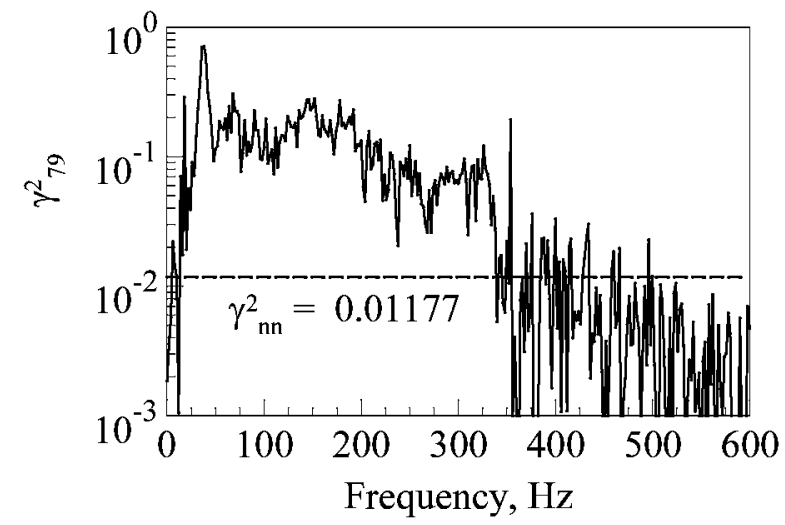

(b) Coherence function between microphone at $130^{\circ}$ and CIP1 combustor pressure sensor.

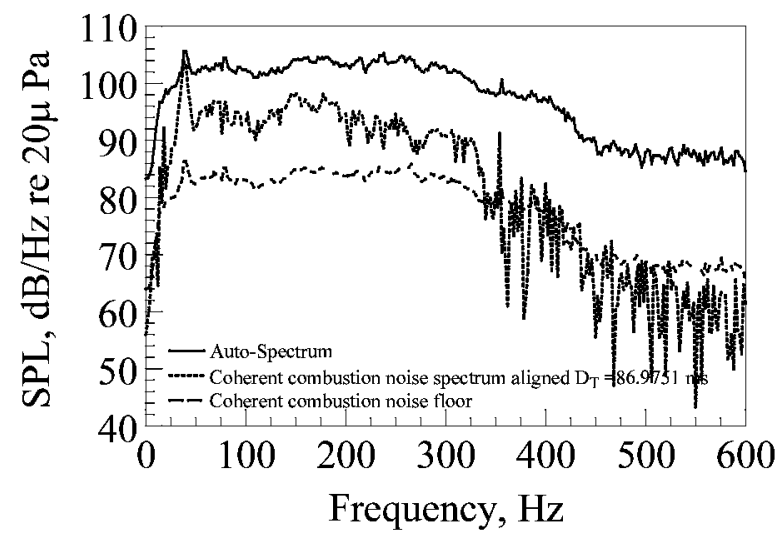

(d) Coherent output power at microphone at $130^{\circ}$ using CIP1 combustor pressure sensor and a $6 \mathrm{~dB}$ ground reflection correction.

Figure 13. Turbofan engine power setting of 48 percent maximum power, microphone at $130^{\circ}$. Signal processing uses aligned signals filtered at $400 \mathrm{~Hz}\left(D_{T}=5700 / 65536=86.98 \mathrm{~ms}\right)$. 


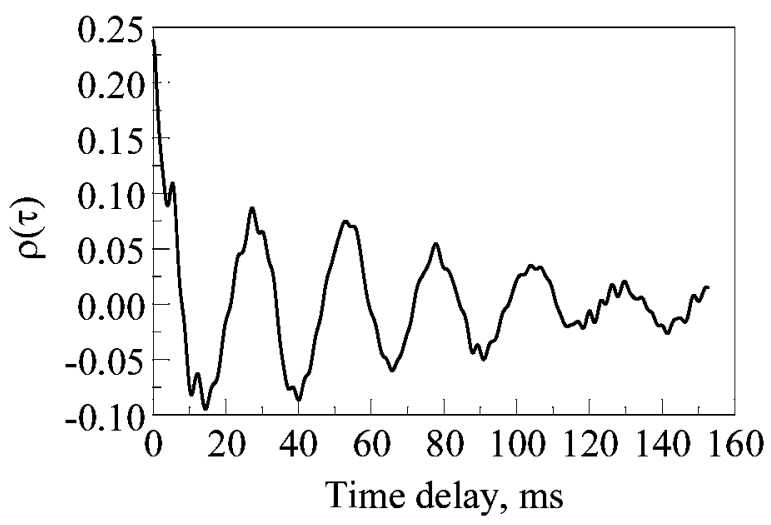

(a) Cross-correlation function between microphone at $130^{\circ}$ and CIP1 combustor pressure sensor.

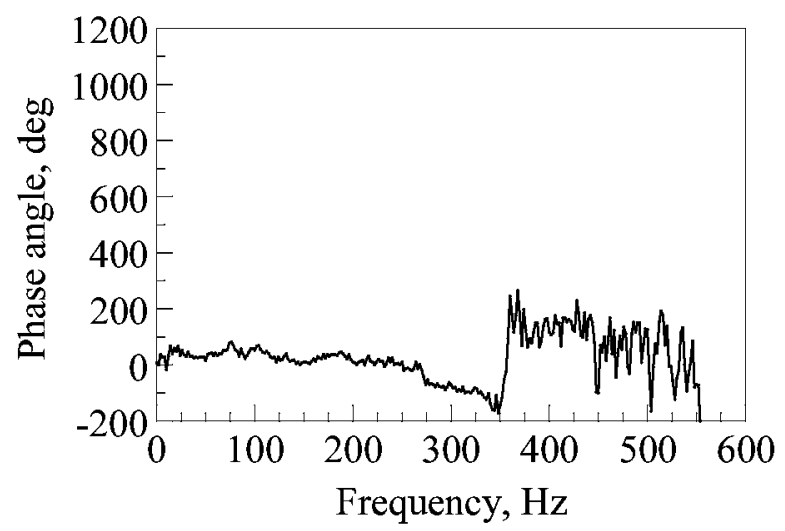

(c) Aligned unwrapped cross-spectrum phase angle between microphone at $130^{\circ}$ and CIP1 combustor pressure sensor.

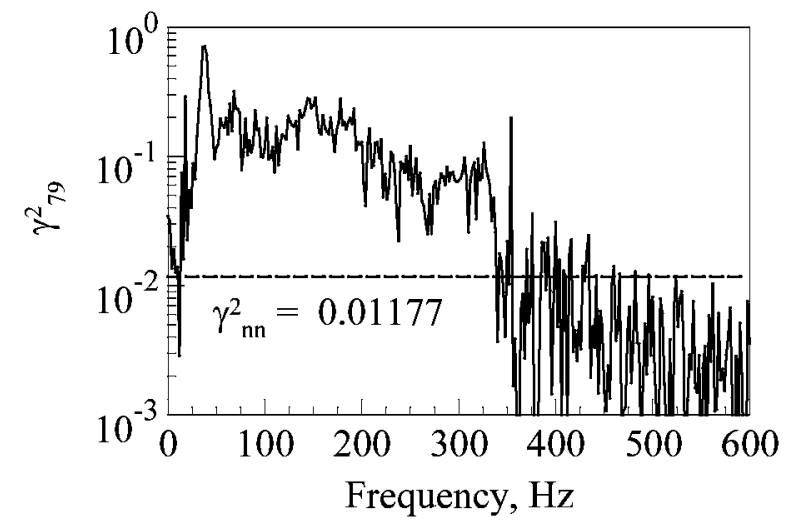

(b) Coherence function between microphone at $130^{\circ}$ and CIP1 combustor pressure sensor.

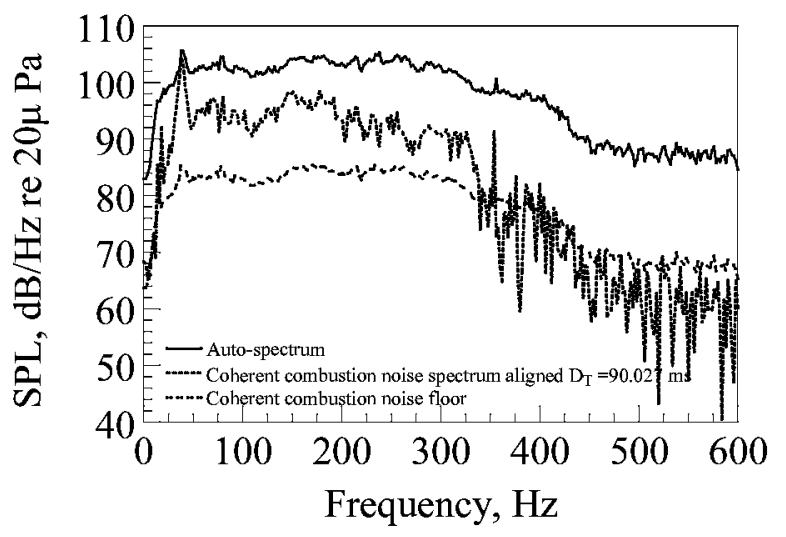

(d) Coherent output power at microphone at $130^{\circ}$ using CIP1 combustor pressure sensor and a $6 \mathrm{~dB}$ ground reflection correction.

Figure 14. Turbofan engine power setting of 48 percent of maximum power. Microphone at $130^{\circ}$. Signal processing done using aligned signals filtered at $400 \mathrm{~Hz}\left(D_{T}=5900 / 65536=90.03 \mathrm{~ms}\right)$. 


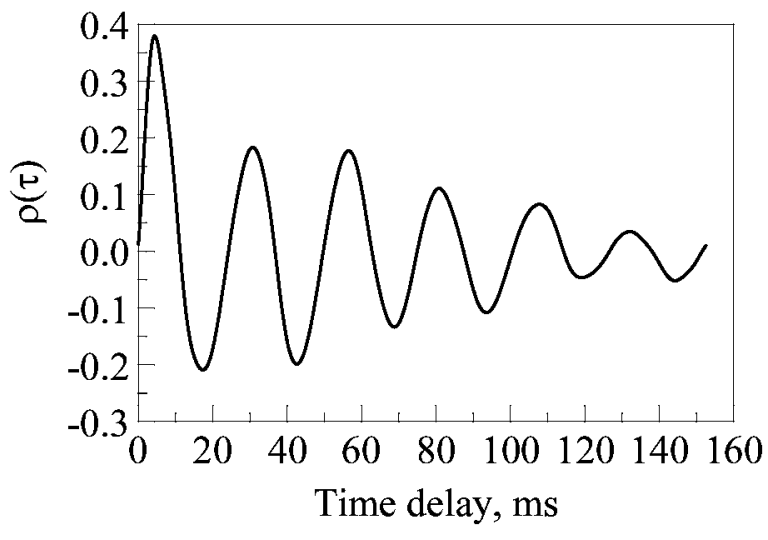

(a) Cross-correlation function between microphone at $130^{\circ}$ and CIP1 combustor pressure sensor.

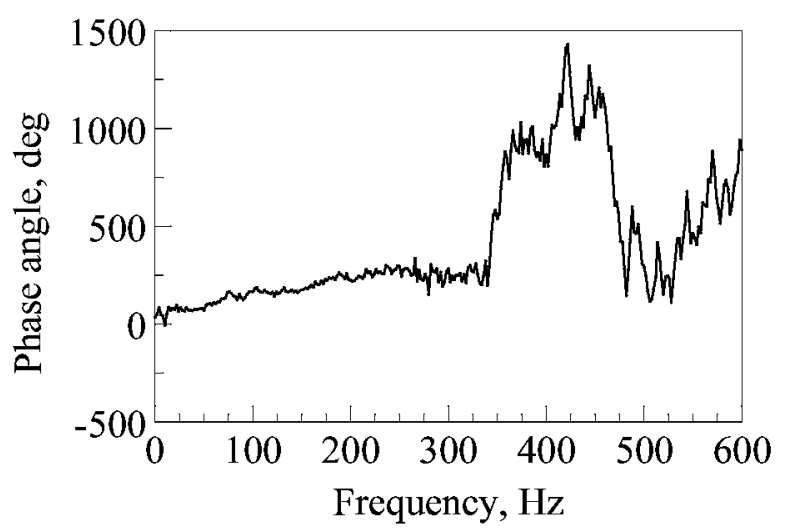

(c) Aligned unwrapped cross-spectrum phase angle between microphone at $130^{\circ}$ and CIP1 combustor pressure sensor.

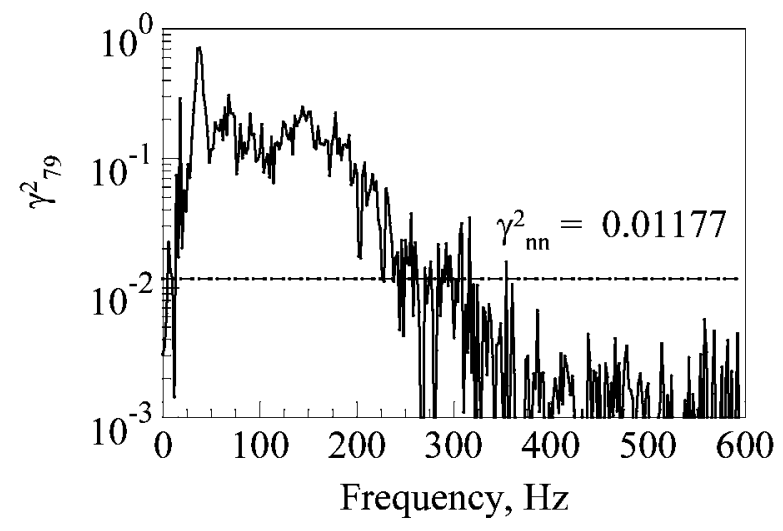

(b) Coherence function between microphone at $130^{\circ}$ and CIP1 combustor pressure sensor.

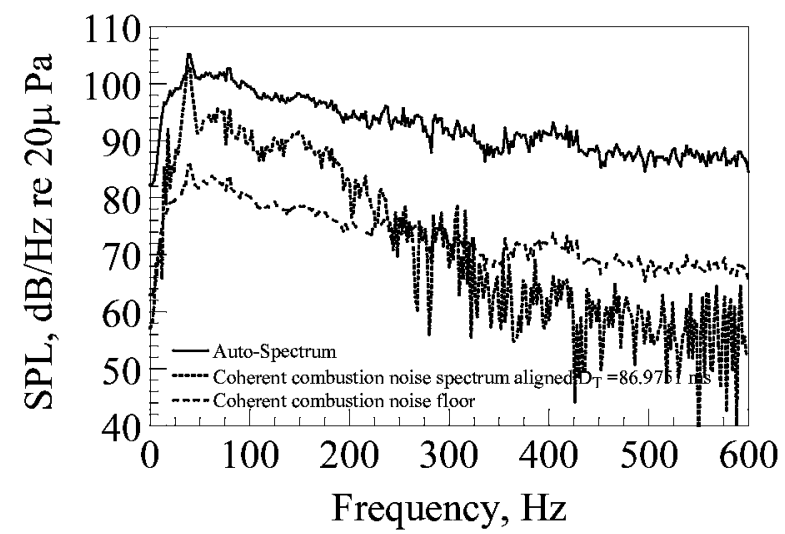

(d) Coherent output power at microphone at $130^{\circ}$ using CIP1 combustor pressure sensor and a $6 \mathrm{~dB}$ ground reflection correction.

Figure 15. Turbofan engine power setting of 48 percent maximum power. Microphone at $130^{\circ}$. Signal processing done using aligned signals filtered at $150 \mathrm{~Hz}\left(D_{T}=5700 / 65536=86.98 \mathrm{~ms}\right)$. 


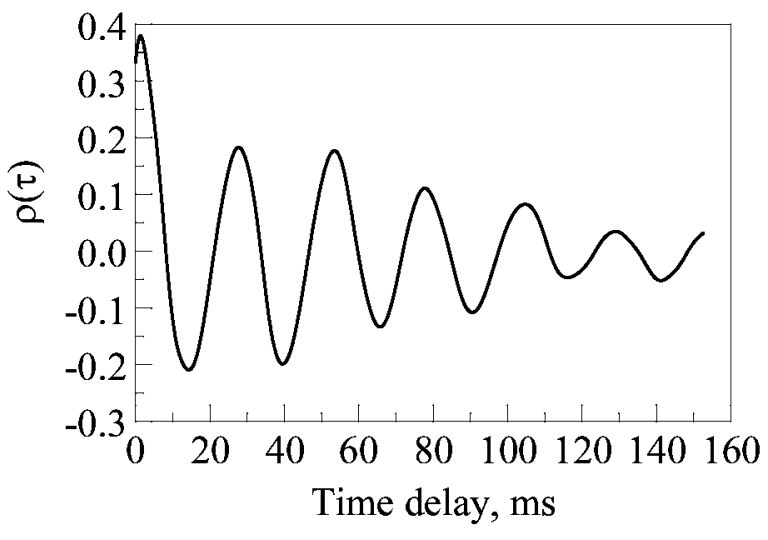

(a) Cross-correlation function between microphone at $130^{\circ}$ and CIP1 combustor pressure sensor.

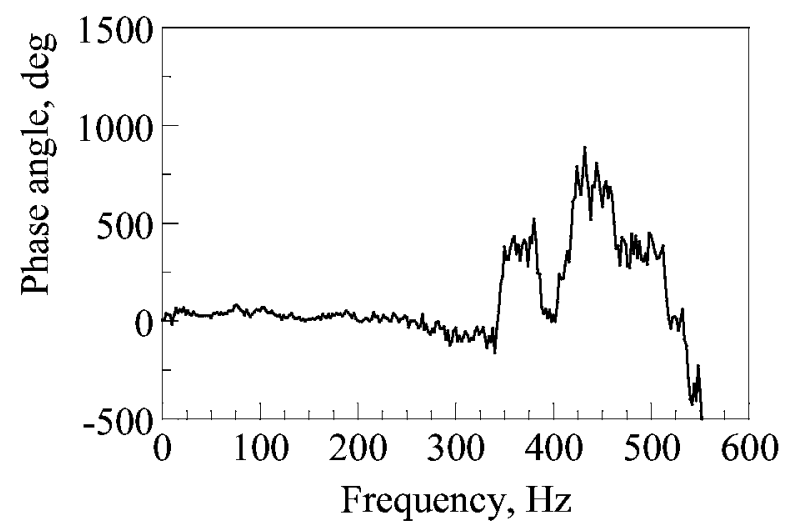

(c) Aligned unwrapped cross-spectrum phase angle between microphone at $130^{\circ}$ and CIP1 combustor pressure sensor.

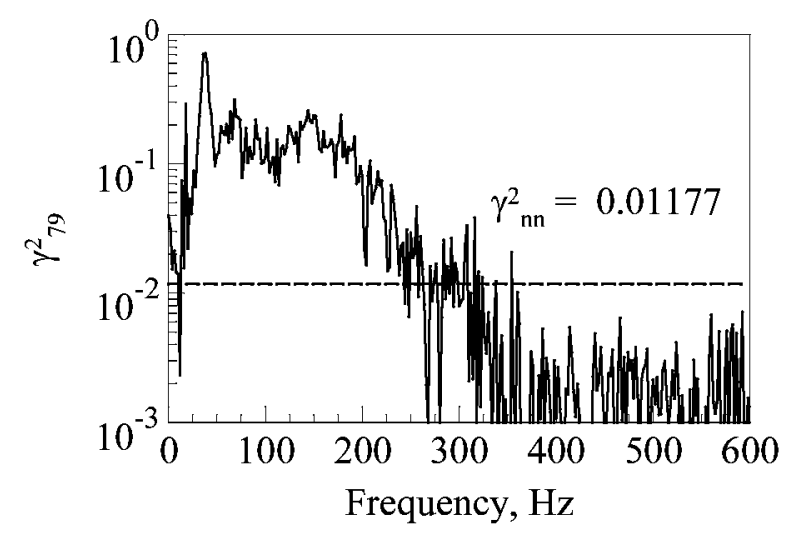

(b) Coherence function between microphone at $130^{\circ}$ and CIP1 combustor pressure sensor.

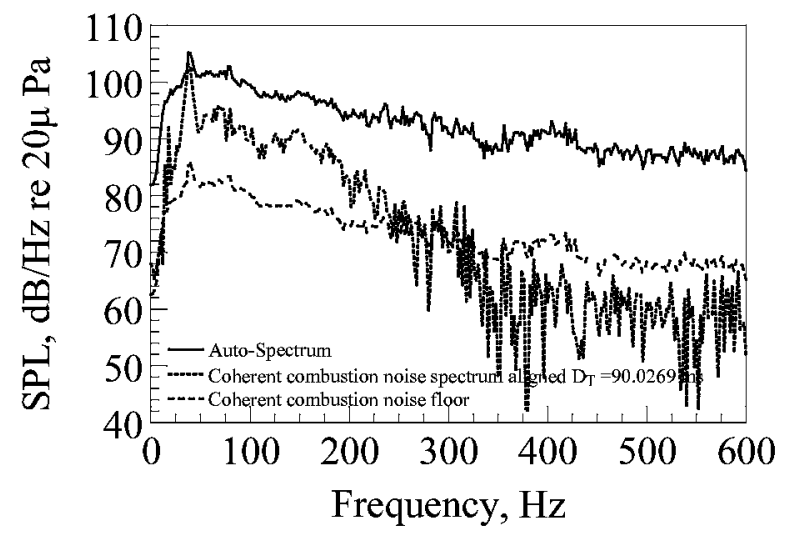

(d) Coherent output power at microphone at $130^{\circ}$ using CIP1 combustor pressure sensor and a $6 \mathrm{~dB}$ ground reflection correction.

Figure 16. Turbofan engine power setting of 48 percent of maximum power. Microphone at $130^{\circ}$. Signal processing done using aligned signals filtered at $150 \mathrm{~Hz}\left(D_{T}=5900 / 65536=90.03 \mathrm{~ms}\right)$. 


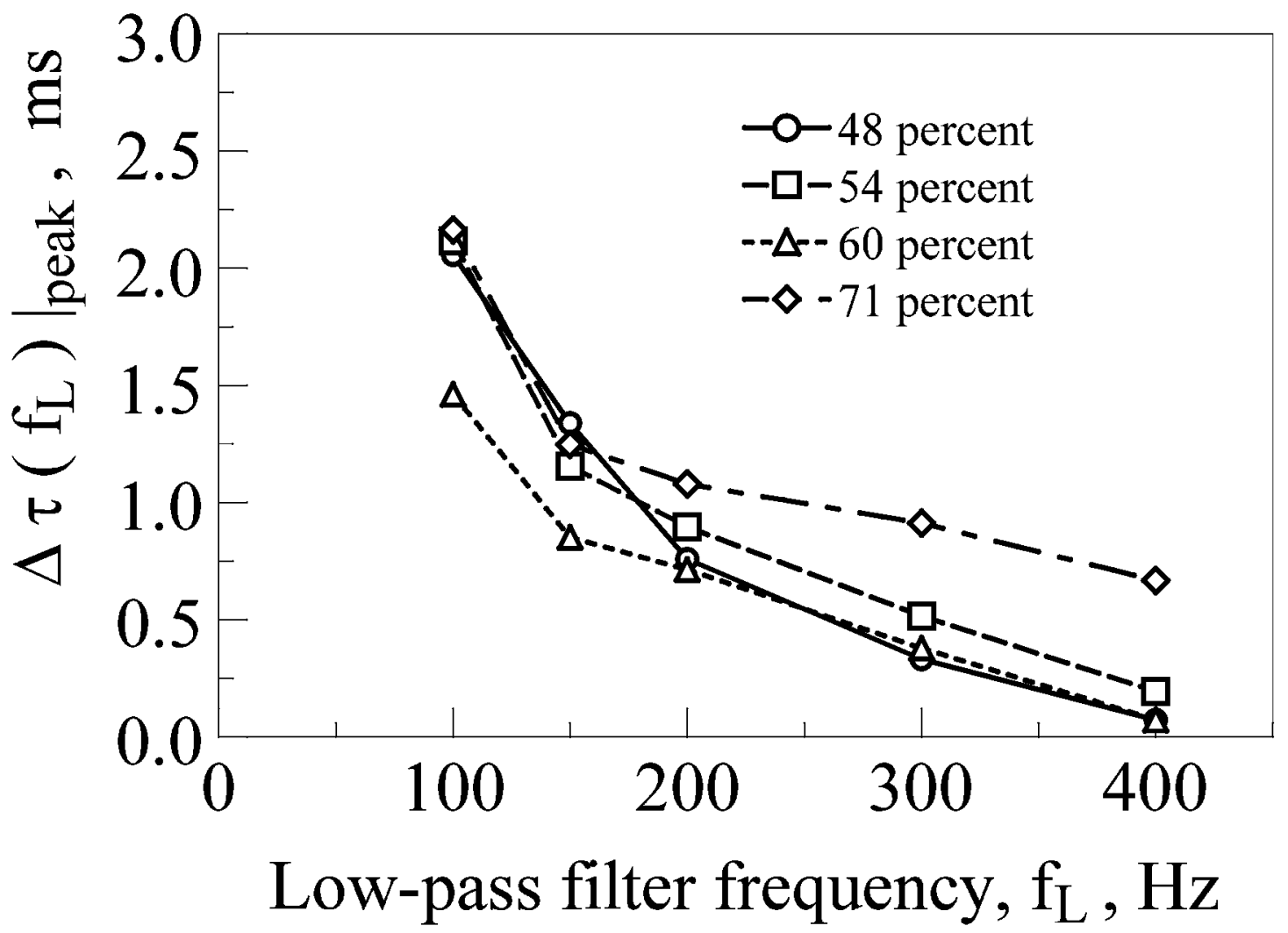

Figure 17. Time delay at peak value of cross-correlation function of low-pass filtered signals as a function of filter design frequency less $90 \mathrm{~ms}$. 


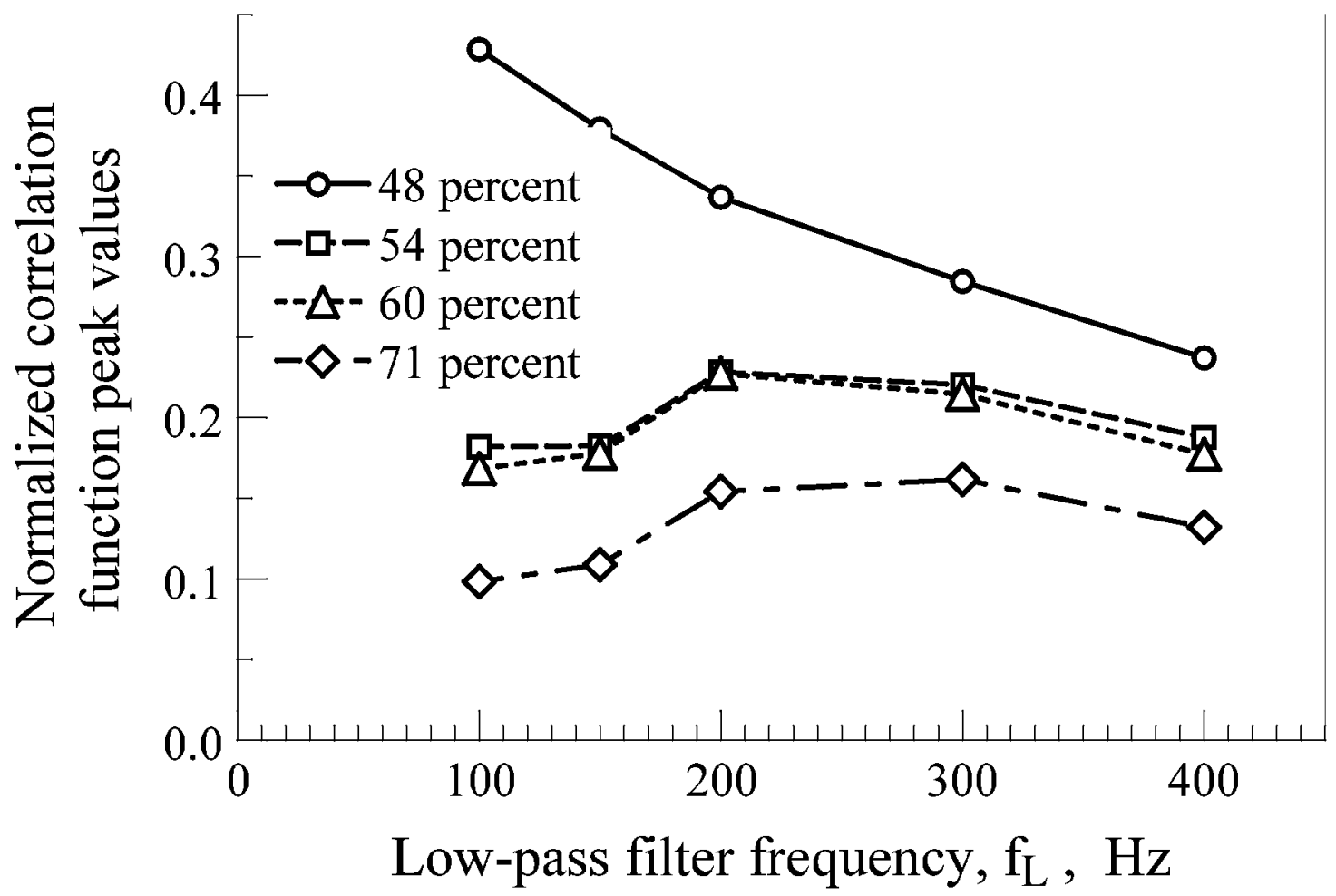

Figure 18. Peak values of low-pass filtered cross-correlation function as a function of filter design frequency. 


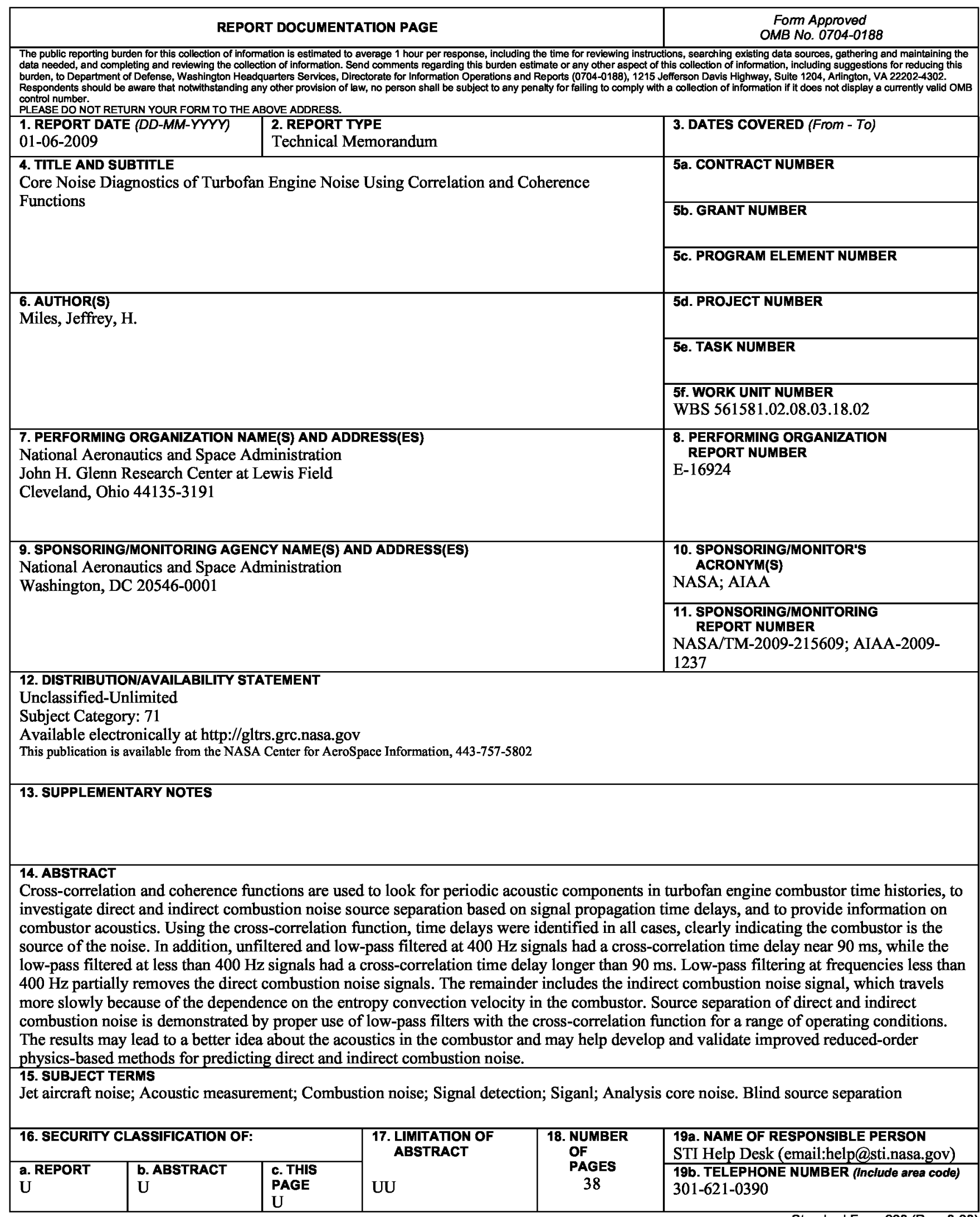



